\title{
Evidence and origin of different types of sedimentary organic matter from a Paleoproterozoic orogenic Au deposit
}

\author{
Aileen Mirasol-Robert ${ }^{\mathrm{a}, \mathrm{b}, \mathrm{c}, *}$, Hendrik Grotheer ${ }^{\mathrm{b}}$, Julien Bourdet $^{\mathrm{d}}$, Alexandra Suvorova ${ }^{\mathrm{e}}$, \\ Kliti Grice ${ }^{\mathrm{b}}$, T. Campbell McCuaig ${ }^{\mathrm{a}, \mathrm{c}, \mathrm{f}}$, Paul F. Greenwood ${ }^{\mathrm{a}, \mathrm{b}}$ \\ a Centre for Exploration Targeting, School of Earth Sciences, The University of Western Australia, 35 Stirling Highway, Perth WA 6009, Australia \\ b Western Australia Organic and Isotope Geochemistry Centre, The Institute for Geoscience Research, Department of Chemistry, Curtin University, GPO Box U1987, Perth \\ WA 6845, Australia \\ ${ }^{c}$ Australian Research Council Centre of Excellence for Core to Crust Fluid Systems, School of Earth Sciences, The University of Western Australia, 35 Stirling Highway, \\ Perth WA 6009, Australia \\ d CSIRO, ARRC, 26 Dick Perry Avenue, Kensington WA 6151, Australia \\ e Centre for Microscopy, Characterisation \& Analysis, The University of Western Australia, 35 Stirling Highway, Perth WA 6009, Australia \\ ${ }^{\mathrm{f}}$ BHP, 125 St. Georges Terrace, Perth WA 6000, Australia
}

\section{A R T I C L E I N F O}

\section{Keywords:}

Organic geochemistry

Orogenic gold

Hydrothermal fluid

Hydropyrolysis

Laser Raman spectroscopy

HRTEM

\begin{abstract}
A B S T R A C T
Carbonaceous material (CM) is thought to be a key reductant contributing to the formation of large Au deposits, but there has been much speculation about its source, molecular composition and reactivity. The first successful analytical retrieval of organic compounds from a thermally over-mature $\left(>550{ }^{\circ} \mathrm{C}\right.$ ) Paleoproterozoic CosmoHowley Orogenic Au deposit was recently achieved by Robert et al. (2016). Here, we have evaluated the nature of the CM associated with this high temperature Au mineralisation via an integrated analytical approach which combined high-resolution in situ laser Raman spectroscopy, micro to nano-scale imaging (e.g., EELS, HAADFSTEM, and HRTEM) and molecular and isotopic geochemistry. We identified two distinct CM types: $\mathbf{C M}_{k e r}-$ an ubiquitous highly graphitic kerogen typical of high-grade metamorphic conditions formed by regional metamorphism; and $\mathbf{C M}_{\boldsymbol{f d}}$ - small sub-microscopic inclusion-like nodules of highly disordered carbon rich in polycyclic aromatic hydrocarbons (PAHs), coincident within the Au-bearing sulfide minerals in hydrothermal vein regions. The paragenetic emplacement and molecular characteristics of $\mathbf{C M}_{f d}$ suggests a formation by metasomatic processes and introduction by a hydrothermal fluid which might also have co-transported Au. $\mathbf{C M}_{\text {ker }}$ and $\mathbf{C M}_{\boldsymbol{f} \boldsymbol{d}}$ gave different Raman spectra indicative of their contrasting origin and structural response to regional and contact metamorphic history and subsequent metasomatism of the Cosmo-Howley deposit. Raman signals indicated $\mathbf{C M}_{k e r}$ had a graphitic like structure whereas $\mathbf{C M}_{f d}$ comprised high concentrations or clusters of PAHs. The broad range of Raman spectra detected here (and by others in similar studies) was likely due to the mixed signals of these two types of CM. The $\delta^{13} \mathrm{C}$ values of PAH products released via the HyPy treatment of the parent and sequentially demineralised kerogen fractions were measured to be in the range of -20 to $-30 \%$, indicative of an organic biopolymeric origin. The $\delta^{13} \mathrm{C}$ values of PAHs products decreased with demineralisation, concomitant with an increase in their concentrations and affinity to the sulfide-minerals (and associated $\mathbf{C M}_{\boldsymbol{f d}}$ ) suggesting a close relationship. The localised (within $20 \mathrm{~mm}$ ) co-occurrence of different CM types and apparent abundance correlation of $\mathbf{C M}_{f \boldsymbol{d}}$ with $\mathrm{Au}$ and sulfides suggests Au mineralisation might be supported by specific CM types, and these relationships should be evaluated further including on a wider Au deposit scale.
\end{abstract}

\section{Introduction}

Orogenic type Au deposits are commonly associated with carbonaceous sediments suggesting carbon materials may be an important factor in key Au mineralisation processes. Many orogenic gold deposits and indeed Au-bearing fluids occur in Proterozoic terranes with predominantly carbonaceous shales or sedimentary host rocks (Goldfarb et al., 2001; Groves et al., 2003). An important general role may be the carbon reduction of ore-forming fluids. The reductive capacity of carbon-rich beds have been implicated in high temperature Au mineralisation of Cosmopolitan (Cosmo) - Howley Au deposits from the Pine Creek Orogen (PCO) (Matthäi et al., 1995a,b; Matthäi and Henley,

\footnotetext{
* Corresponding author at: Centre for Exploration Targeting, School of Earth Sciences, The University of Western Australia, 35 Stirling Highway, Perth WA 6009, Australia.

E-mail address: aileen.robert@research.uwa.edu.au (A. Mirasol-Robert).
} 
1996). In the PCO alone, there are over 250 Au mineral occurrences with a total Au resource of $9 \mathrm{Moz}$, and an even larger number of non-Au mineral occurrences (Ahmad and Hollis, 2013; Hollis and Wygralak, 2012; Wygralak et al., 2005). Several studies of orogenic gold deposits have proposed that carbonaceous material (CM) may be directly involved in Au metallogenesis including by preferential precipitation of $\mathrm{Au}$ in carbonaceous rocks via reduction of ore-bearing fluid at vein margins (e.g., Abitibi Belt, Ontario-Quebec and Northern British Columbia and Canada respectively; Springer, 1985). Gold and sulfide precipitate during reduction of the fluid by hydrothermal graphite has been interpreted in the Otago Schist, New Zealand (Craw et al., 1999) suggesting that hydrothermal mobilisation and concentration of graphite may be a necessary precursor to the later more restricted gold mineralisation (Henne and Craw, 2012). A strong association of Au and hydrothermal graphite is known (e.g., Dissanayake, 1993).

Several different types of CM have been reported in orogenic type $\mathrm{Au}$ deposits. Recent Raman and petrographic analysis identified four different types of CM within the Macraes gold field of the Otago Schist (Hu et al., 2015). The prehnite-pumpellyite to lower greenschist metamorphic grade samples showed: (1) a low-maturity CM coexisting with framboidal Au-enriched pyrite, indicating an in situ sedimentary origin, with a potential association to the source of gold; (2) low crystallinity CM found in low metamorphic grade samples likely to have been deposited from fluids unrelated to gold mobilization; (3) highest maturity $\mathrm{CM}$ found in lower greenschist facies rocks, where the CM bands cross cutting the foliation are thought to have been transported by fluids and; (4) CM with slightly lesser maturity than 3 found in mineralised rocks in association with sulfide minerals and gold likely to have a common hydrothermal origin (Hu et al., 2015). The average value of the laser Raman signal ratio R1 (intensity D1/G signals) for CM Types $1-4$ show increasing values of $\sim 0.89, \sim 1.03, \sim 1.20$ and $\sim 1.53$ coincident with their increasing thermal maturity. This was surprising since lower R1 values are expected for very high maturity or metamorphic CM (Beyssac et al., 2002). CM associated with hydrothermal fluids (detected as small veinlets in hydrothermally altered rocks and in quartz veins or irregular accumulations parallel or sub-parallel to Ctype cleavage within the shear zones) was also distinguished from metamorphosed CM in a detailed geochemical study of several large West African Au deposits (Kř́bek et al., 2015). The metamorphosed CM of these deposits was furthermore inferred to contain significant biogenically derived organic component on the basis of light $\delta^{13} \mathrm{C}_{\text {org }}$ values ( -33.1 to $-26.2 \%$, VPDB).

Organic matter $(\mathrm{OM})$ may potentially share a large number of intimate relationships with Au during its transportation, accumulation or deposition (e.g., redox or catalytic reactions, solubility changing complexations, co-transportation in hydrothermal fluids or co-accumulation in porous rocks; Gize, 2000; Greenwood et al., 2013). Au has quite unusual organo-metallic properties (i.e., distinct from fellow group $1 \mathrm{~b}$ elements $\mathrm{Cu}$ and $\mathrm{Ag}$ ) including a competence for low redox state complexation with OM (Gize, 2000). As a soft Lewis acid it can complex with easily polarizable ligands (e.g., low molecular-weight organic acids or thiosulfides) and these interactions have long been proposed to aid the transformation and precipitation of certain Au minerals (Fetzer, 1946, 1934; Freise, 1931; Gregoire, 1985; Parnell and McCready, 2000; Seward, 1973). Colloidal or other protective organic layers around $\mathrm{Au}$ can also assist its subsurface mobility and transportation (Gatellier and Disnar, 1989). Therefore, the identification and understanding of specific organic-Au interactions may even assist Au-exploration strategies.

We recently reported preliminary Laser Raman (LR) data that distinguished two different types of CM in a metasediment (sample CO-24) from the Cosmo Howley Paleoproterozoic orogenic $\mathrm{Au}$ deposit, Northern territories, Australia (Robert et al., 2016). One CM type was of high metamorphic grade or crystallinity and representative of the sedimentary matrix, whilst the other $\mathrm{CM}$ reflected a relatively high degree of disorder and seemed to be spatially associated with sulfide veins throughout the sediment. The Raman inferred temperatures for these two CM's were $\sim 400{ }^{\circ} \mathrm{C}$ and $\sim 300{ }^{\circ} \mathrm{C}$, respectively (Robert et al., 2016), both substantially lower than fluid inclusion and mineralogically inferred temperatures of $>550{ }^{\circ} \mathrm{C}$ (Matthäi et al., 1995a). Depositional temperatures in excess of $550{ }^{\circ} \mathrm{C}$ would be consistent with the documented deformation, metamorphic and hydrothermal fluid characteristics of this deposit (Bajwah, 1994; Ewers et al., 1985; Matthäi et al., 1995a,b; Matthäi and Henley, 1996; Needham et al., 1988; Partington and McNaughton, 1997). The relatively lower temperatures implied by the Raman analysis suggests these data must be subject to other influences besides thermal maturation.

We also previously detected hydrocarbon products from sample CO24 , which with $20 \%$ TOC was the most organic rich of all sampled cores, by combining the novel approaches of catalytic Hydropyrolysis (HyPy), sequential demineralisation and high resolution in situ microscopy (Robert et al., 2016). Specific mineral-organic interactions were identified by the detection of different polycyclic aromatic hydrocarbons (PAHs) and alkanes from the HyPy treatment of OM liberated by the successive removal of different mineral constituents (i.e., suggesting different $\mathrm{OM} / \mathrm{CM}$ types adsorbed to different mineral assemblages; Robert et al., 2016). Furthermore, the concentrations of the dominant PAH products increased with each demineralisation step, indicating a generally strong affinity for mineral substances. This inorganic interaction potentially protected their structural precursors from thermally promoted reactions, and consequently mute hydrocarbon maturity indicators. The major HyPy released hydrocarbon products were 2-7 ring aromatics, which was consistent with the predominantly aromatic based structure interpreted by Raman characterisation.

The occurrence of two different types of CM at Cosmo Howley has possible implications on the timing of the Au-mineralisation and the participation of a specific CM type in ore formation processes. To more thoroughly evaluate the micro-scale distribution and inorganic relationship of CM types in CO-24 we have conducted many additional LR analysis across a hydrothermal vein rich transect of the sediment. The CM characterisation was further complemented by advanced imaging techniques including high-resolution transmission Electron Microscopy (HRTEM), high angle annular dark field scanning transmission electron microscopy (HAADF-STEM) and electron energy loss spectroscopy (EELS). The $\delta^{13} \mathrm{C}$ values of the most abundant PAHs and selected aliphatic products released by HyPy treatment of the parent and three demineralised kerogen fractions of CO-24 were also measured here to further investigate the origin and potential indigeneity of these hydrocarbons.

\section{Methods}

\subsection{Sample information}

All analyses were conducted on a sedimentary sample (CO-24) from Cosmo Howley, Northern Territory Australia. CO-24 represents a high TOC ( $\sim 20 \mathrm{wt} \%)$ section of a core taken from a drill-hole situated at the apex of the anticline at the boundary of the carbonaceous-rich Koolpin Formation and the Au mineralised units (Fig. 1) where maximum hydrothermal fluid flow occurred. This mineralisation boundary was exposed to peak metamorphic temperature of $>550{ }^{\circ} \mathrm{C}$ based on mineralogy and fluid inclusion data (Matthäi et al., 1995a). There have been several detailed accounts of the geology and stratigraphy of the Cosmo Howley Au deposit (Matthäi et al., 1995a,b; Matthäi and Henley, 1996; Partington and McNaughton, 1997; Robert et al., 2016).

\subsection{Raman spectroscopy}

\subsubsection{Sample preparation and analysis}

Mechanically polished thin sections of CO-24 (Fig. 2A and B) were prepared for detailed in situ LR spectroscopic analysis. We also conducted a LR characterisation of demineralised kerogen fraction (DMK- 

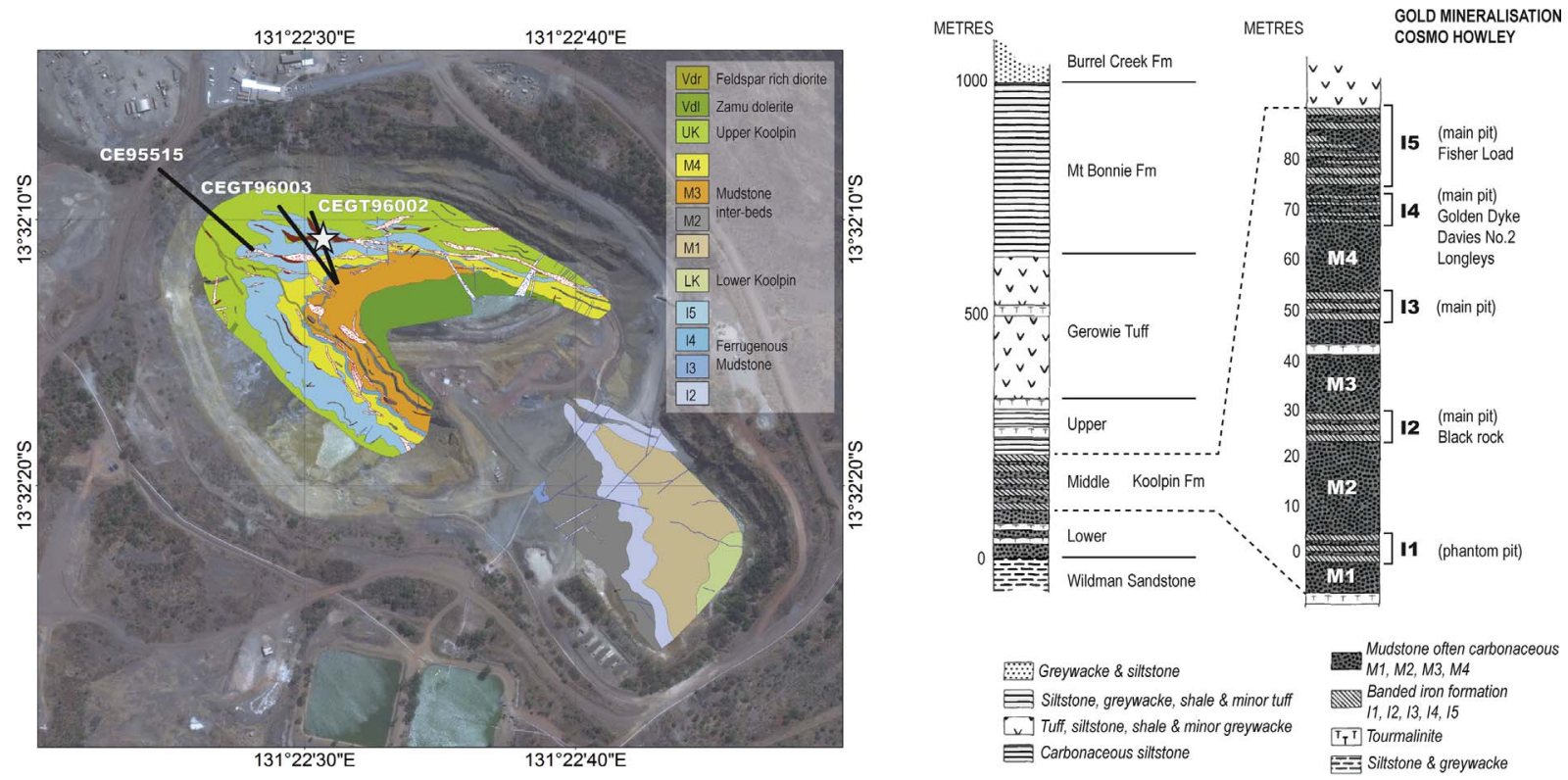

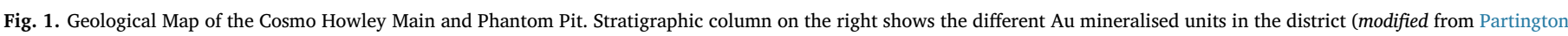
and McNaughton, 1997). Also shown is the trace of the several drill holes - location of CO-24 is indicated by the star.

3) of CO-24 before and after HyPy processing to establish any changes in the isolated kerogen fraction. DMK-3 isolation was detailed in Robert et al., 2016. Powdered DMK-3 was smeared onto a clean glass slide for Raman measurements. The LR measurements conducted on DMK-3 preand post-HyPy treatment helped evaluate the potential influence of the HyPy treatment and related sample preparation on the LR analysis of kerogen samples, and helped interpret the in situ LR analysis of CO-24.

The laser Raman spectra were acquired on a Horiba ${ }^{\circledR}$ LabRAM HR Evolution instrument using a $600 \mathrm{~g} / \mathrm{mm}$ grating, a Synapse visible detector and $532 \mathrm{~nm}$ incident radiation produced by a Torus $100 \mathrm{~mW}$ diode laser (Laser Quantum). To avoid polarisation interference of the Raman signals, the laser beam was depolarised using a quarter wave plate aimed perpendicular to the surface of the thin section and focused using a $100 \times$ objective with a numeric aperture of 0.90 . Acquisition time was $10 \mathrm{~s}$ and there were 3 accumulations. The laser power was reduced to $0.3 \mathrm{~mW}$ using filters to avoid damage to the sample surface. The data were collected in the maximum $250-3500 \mathrm{~cm}^{-1}$ range to capture both first (1100-1800 $\mathrm{cm}^{-1}$ ) and second $\left(2500-3100 \mathrm{~cm}^{-1}\right.$ ) order Raman bands of carbon and associated minerals.

A Gaussian-Lorentzian curve-fitting procedure was applied to the LR spectra to help resolve peaks as described by Kouketsu et al. (2014) using MagicPlot V2.5.1 software (Magicplot Systems LLC, Saint Petersburg, Russia). Individual CM Raman spectra were background corrected by subtracting a spline baseline. The area $(\boldsymbol{A})$, height/intensity $(\boldsymbol{I})$, centre shift position $(\boldsymbol{X})$ and full width at half maximum (FWHM) were calculated for all Raman spectral peaks.

The CM was initially measured under transparent minerals such as mica and quartz to avoid artificially induced disordered C signals (Beyssac et al., 2003). With this approach, however, the CM close to mica often gave highly varying intensities of first order Raman bands (i.e., D1 and G peaks). Thus, the Raman spectroscopy of CM was systematically measured irrespective of its position or affinity to any mineral. Furthermore, several control Raman spectra of predominant minerals (e.g., pyrite, quartz, mica) in proximity to the $\mathrm{CM}$ were measured to assess the potential mixing of signals from multiple CM types and the influence of mineral content of the sediment on the Raman spectra.

A total of 125 laser Raman analyses were conducted on 11 separate zones (Z1-Z11; Fig. 3) of CO-24 reflecting different mineral assemblages. The mineral assemblages and related element relationships were identified from Combined Back Scatter (CBS) SEM and EDS maps (Fig. 3B, A-a-l) on regions I) sediment matrix; II) boundary between I and III; III) sulfide vein rich region. The 11 separate zones (Z1-Z11) on which detailed LR analyses were conducted to measure distribution and occurrence of associated major mineralogical phases are shown in Fig. 3B and C. Higher resolution analyses were performed on zones (e.g., Zone 7) where larger ranges of Raman signal reflected greater CM variance.

\subsubsection{The Raman spectra of PAHs and aromatic rich carbon materials}

2.2.3.1. PAHs. Raman analysis of CM represents a measure of the interaction of functional group atoms and can distinguish the structural variances of different samples. Fig. 4A and B shows the Raman spectra of different aromatic compounds of varying size and molecular orientation. Distinctive Raman features of benzene $\left(\mathrm{C}_{6} \mathrm{H}_{6} ; \mathrm{Fig}\right.$. 4A-i), compared to its saturated equivalent cyclohexane $\left(\mathrm{C}_{6} \mathrm{H}_{12}\right.$; Fig. $\left.4 \mathrm{~A}-\mathrm{ii}\right)$, include (i) no $\mathrm{CH}_{2}$ vibrational frequencies (present in cyclohexane); (ii) $\mathrm{C}-\mathrm{C}$ stretching at a relatively high frequency; and (iii) the occurrence of $\mathrm{C}=\mathrm{C}-\mathrm{C}=\mathrm{C}$ and $\mathrm{C}=\mathrm{C}$ stretch of $\mathrm{E} 2 \mathrm{~g}$ symmetry near $1600 \mathrm{~cm}^{-1}$ (Fig. 5A right) (Ferrari and Robertson, 2000; Mayo et al., 2004; Shimanouchi, 1973). The latter conjugated signals represents the G band common to the Raman spectra of naturally occurring CMs which are absent in cyclohexane.

In the case of larger polycyclic aromatic compounds such as coronene $\left(\mathrm{C}_{24} \mathrm{H}_{12}\right.$; Fig. 4A-iii) and hexabenzocoronene $\left(\mathrm{HBC} ; \mathrm{C}_{42} \mathrm{H}_{18}\right.$; Fig. 4A-iv) another series of Raman spectral bands becomes activated in the $\sim 1200-1400 \mathrm{~cm}^{-1}$ region (D band modes; orange shaded region; Fig. 4A and B). This is mainly due to the A1g symmetry breathing modes of $\mathrm{C}$ in the aromatic ring structure (Fig. 5A left) and corresponds to the D1 band common to the Raman spectra of disordered CMs. Other peaks in this section may be a result of the ring breathing (A1g) in combination with the in-plane bending of the $\mathrm{C}-\mathrm{H}$ or $\mathrm{C}-\mathrm{C}$ stretching at the edge of the molecules (Maghsoumi et al., 2016). The $\sim 235 \mathrm{~cm}^{-1}$ peak in $\mathrm{HBC}$ is also a breathing mode of $\mathrm{A} 1 \mathrm{~g}$ symmetry from within the aromatic core (see structure of HBC in Fig. 4A-iv).

For increasingly larger PAHs (e.g., $\mathrm{C}_{60} \mathrm{H}_{22}, \mathrm{C}_{72} \mathrm{H}_{26}, \mathrm{C}_{78} \mathrm{H}_{26}, \mathrm{C}_{96} \mathrm{H}_{30}$, $\mathrm{C}_{132} \mathrm{H}_{34}$; Fig. 4B) the peaks in the $\mathrm{D}$ band region are mainly determined by the $\mathrm{C}-\mathrm{C}$ stretching contributions at the edge of the molecule (Castiglioni et al., 2001a,b). Hence, the variations in the D region peaks are due to the variance in the edge phonon eigenvectors (at $\mathbf{K}$ point; see 


\section{A. CO-24 Drill Core}
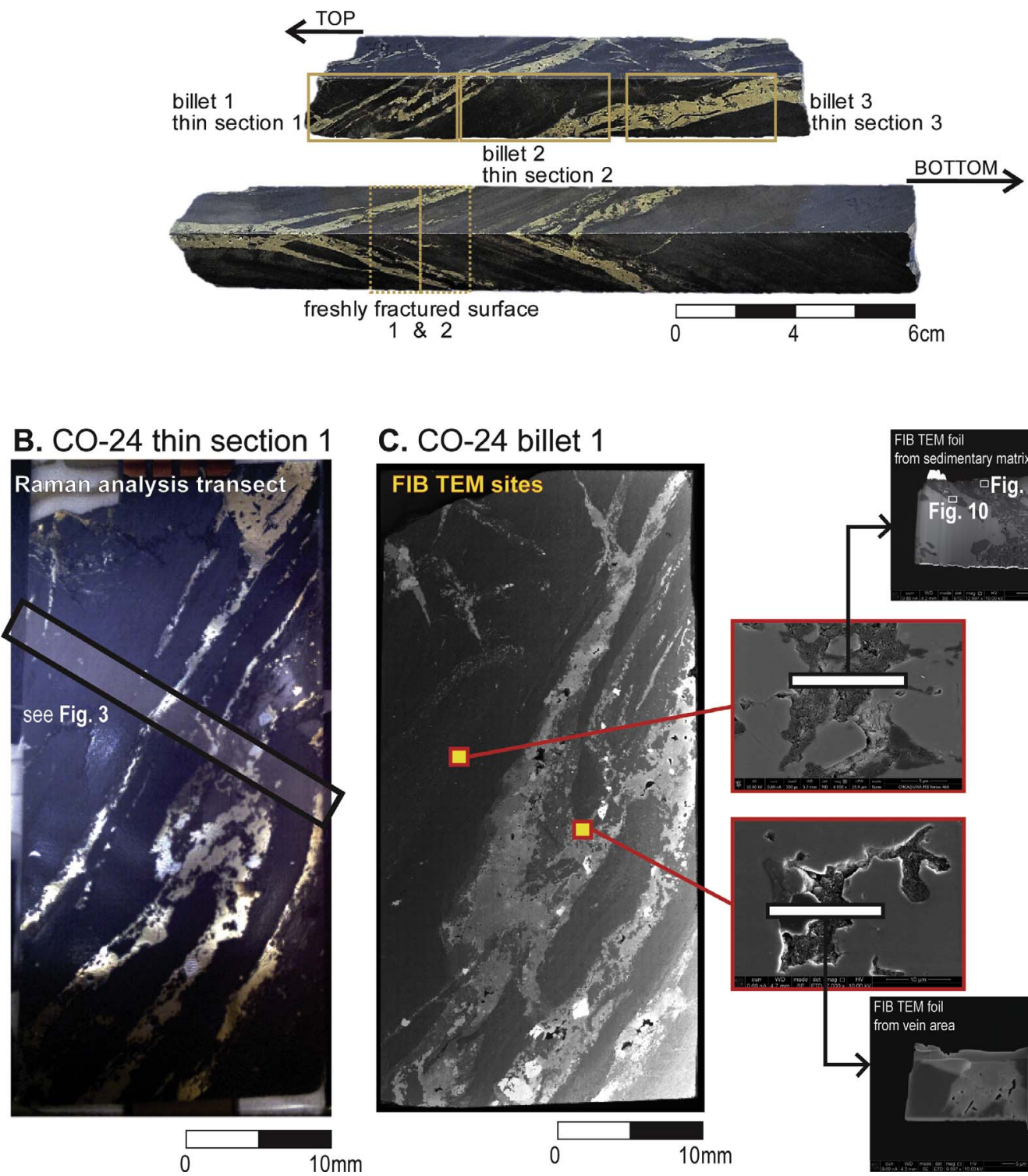

\section{CO-24 billet 1}
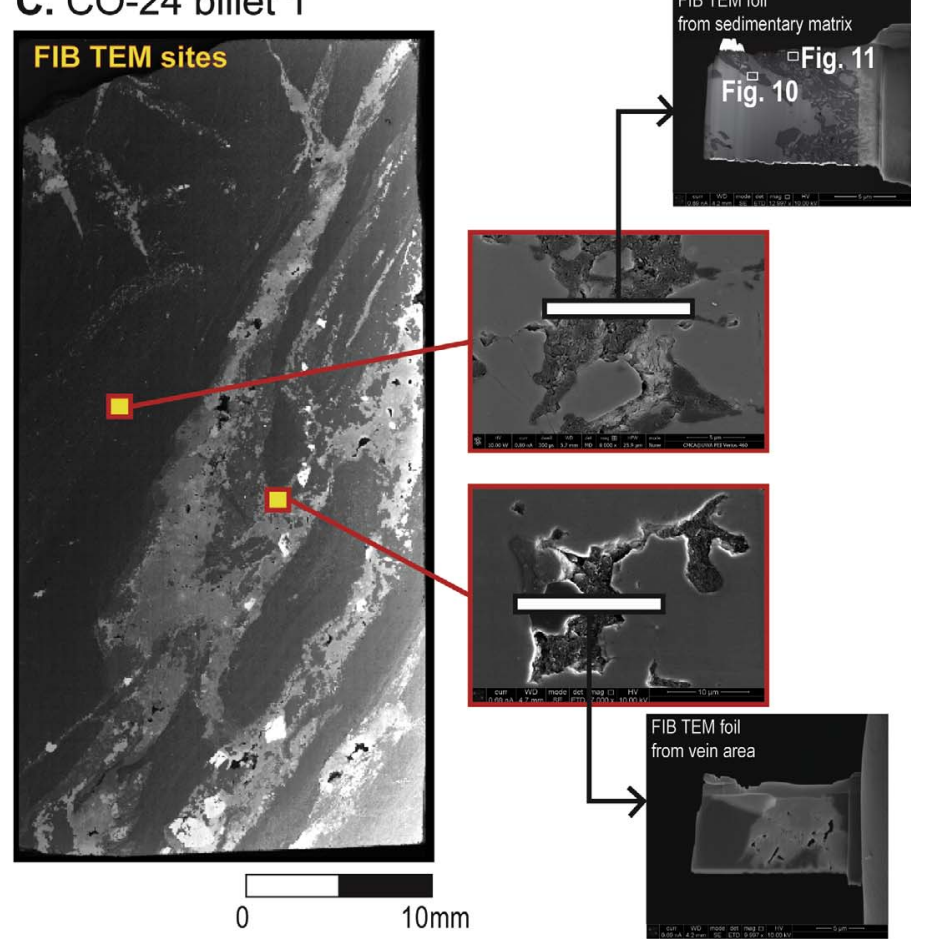

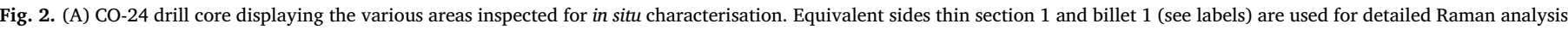

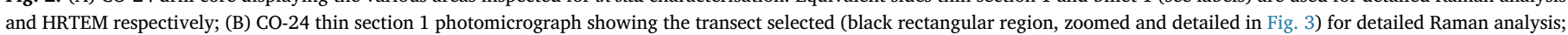

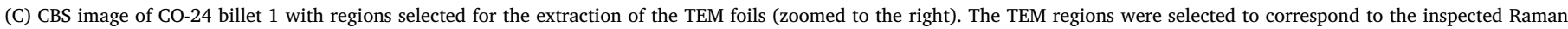
transect of the CM found in (1) sedimentary matrix and (2) sulfide veins.

Fig. 5B) relating to the A1g symmetry (Fig. 5C iTO at K, outward pointing red arrows). Eigenvectors are the vibrational atom displacement due to the laser excitation.

2.2.3.2. Aromatic sheets - graphene and graphite. Pristine graphene sheets (Fig. 4C-i \& ii) essentially present a semi-infinite network of $\mathrm{sp}^{2}$ bonded carbons with no edges (Ferrari and Basko, 2013; Yan and Barron, 2010). Thus, a prominent $\mathrm{G}$ peak $\left(\sim 1583 \mathrm{~cm}^{-1}\right)$ is observed due to the doubly degenerate iTO and iLO phonon modes (equivalent to $\mathrm{C}=\mathrm{C}$ bond stretching of PAHs; $\mathrm{G}$ band; Fig. $5 \mathrm{C}$;) of E2g symmetry $\mathrm{sp}^{2}$ hybridized carbons at $\boldsymbol{\Gamma}$ points (central axis $\boldsymbol{\Gamma}$ shown in Fig. 5B) (Tuinstra and Koenig, 1970). The D modes (i.e., D1 peak) are breathing modes of A1g symmetry involving phonons near the $\mathbf{K}$ zone boundary (Fig. 5C right; outward pointing red arrows) and are inactive in the absence of structural edges (Ferrari, 2007).

The D modes are also sensitive to "defects" or breaks in the symmetry of an infinite carbon honeycomb lattice such as may occur in defective graphene (Fig. 4C-v), amorphous carbons (e.g., black carbon;
Fig. 4C-vi) and other synthetic or naturally occurring graphitic CM (Eckmann et al., 2012). Structural defects may occur at (1) grain boundaries (similar to structural edges of graphite crystals); (2) vacancies (breaks within the aromatic network); or (3) due to a change of carbon-hybridization (e.g., $\mathrm{sp}^{2}$ into $\mathrm{sp}^{3}$ ) (Fig. 5D) (Eckmann et al., 2012; Luo et al., 2012).

Similar to pristine graphene sheets, the Raman spectra obtained from the inner portion of a single graphite crystallite show no D1 peak (Fig. 4C-iii) whereas a D1 peak was evident with analysis near the outer circumference of the crystal where A1g breathing modes are encountered (Fig. 4C-iv; Dresselhaus et al., 2010). The Raman spectra were extracted from the regions shown in the confocal Raman image of the graphite crystallite in Fig. 4C-a for the G-band and Fig. 4C-b for the D-band (Dresselhaus et al., 2010).

A 2D peak (at $\sim 2700 \mathrm{~cm}^{-1}$ ) arises from a two phonon lattice vibrational process (Fig. 5C iTO at $\mathbf{K}$, central pointing red arrows) unrelated to any structural defect (unlike the D1 peak; Ferrari and Basko, 2013). Hence, graphene and graphite consistently give rise to a $2 \mathrm{D}$ 


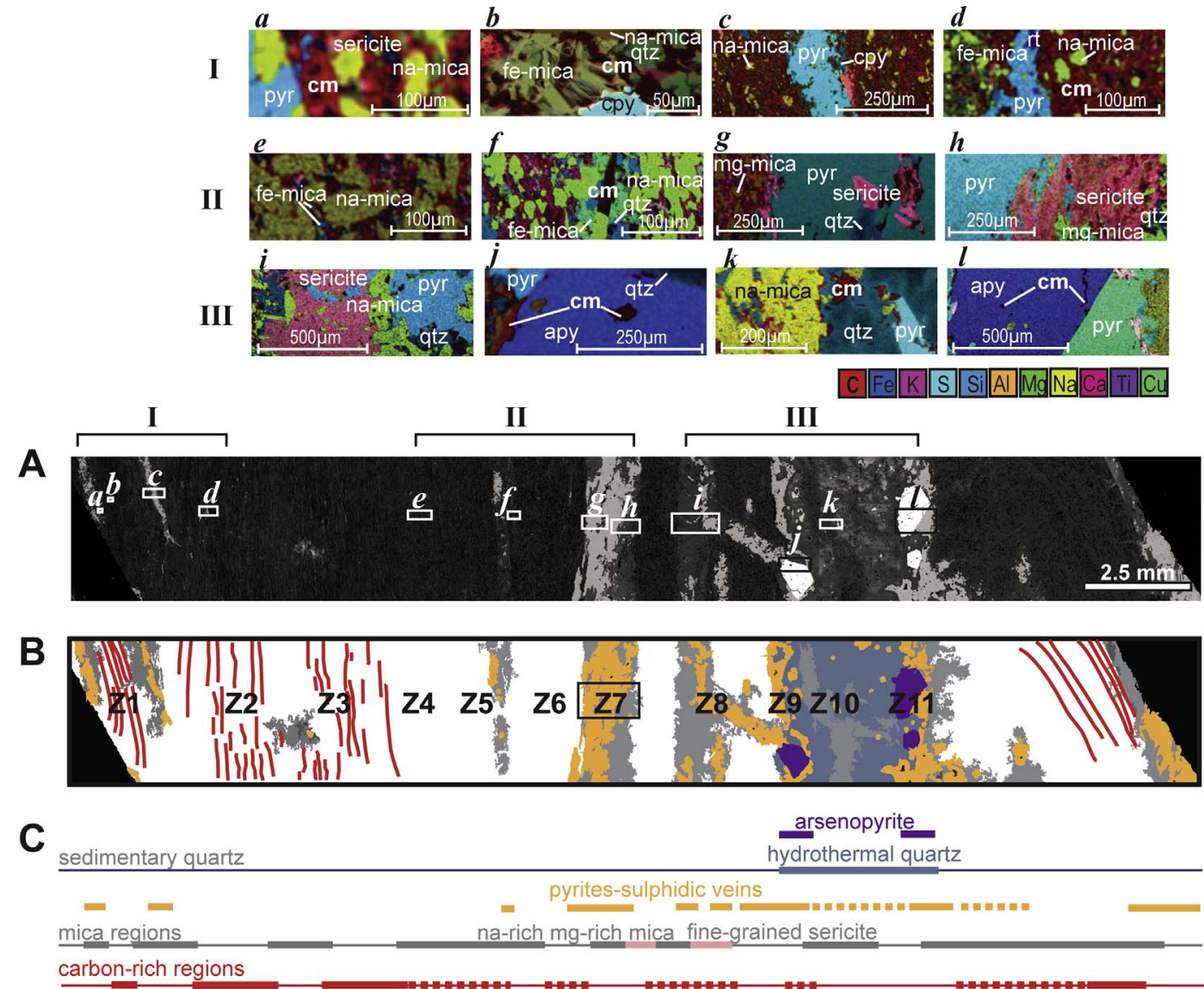

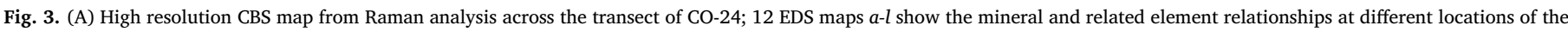

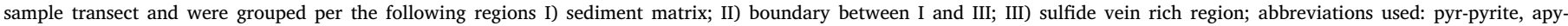

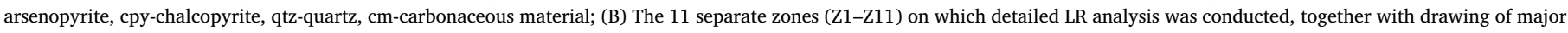
mineralogical phases of CO-24 sample; (C) distribution and occurrence of major mineral phases of CO-24 identified by EDS along the sample transect.

peak, but not always the D1 peak (Fig. 4C-i \& ii). The 2D Raman resonance is also sensitive to the number of layers $(N)$ (Ferrari and Basko, 2013), so will differ in shape/intensity for monolayer and multilayer sheets (high intensity and lower FWHM for 2D in monolayer; lower intensity and wider FWHM for multilayer graphene and graphite respectively; Fig. 4C-i \& ii).

2.2.3.3. Amorphous carbons. Amorphous carbon has no crystal structure and is often referred to as free reactive carbon. Purely amorphous carbon structures are possible, but most amorphous carbon materials include microscopic graphite $\left(\mathrm{sp}^{2}\right.$ bonding) or diamond $\left(\mathrm{sp}^{3}\right)$ structural moieties at crystallite sizes $\left(L_{a}\right)<2 \mathrm{~nm}$ (Pawlyta et al., 2015). Fig. 4C-vi shows the Raman spectra typical of amorphous black carbon. The prominence of the D1 $\left(\sim 1350 \mathrm{~cm}^{-1}\right)$ over the $\mathrm{G}\left(\sim 1600 \mathrm{~cm}^{-1}\right)$ bands reflect a high degree of structural disorder.

The black carbon consists of agglomerated spherical particles (10-100 nm) with distinctive graphitic and amorphous-like moieties. The graphitic-like domains termed as "basic structural units" (BSU) typically consist of 3-4 turbostratically stacked carbon polyaromatic layers (BSU sketch; Fig. 4C-c) and the amorphous parts dominate the core and sometimes form a skin of the primary particles (Pawlyta et al., 2015).

Additional disordered bands D2, D3 and D4 peaks can be resolved on peak deconvolution (Fig. 4C-vi). D3 corresponds to the aromatic ring breathing mode (similar to D1 peak) and $\mathrm{C}-\mathrm{C}$ stretching. The D4 peak is a measure of $\mathrm{sp}^{2}-\mathrm{sp}^{3}$ bonds or vibrations from single and double bonded carbons (e.g., hydrocarbon or aliphatic moieties connected on BSUs) usually observed as a lower energy shoulder of the D1 peak
(Bokobza et al., 2015; Pawlyta et al., 2015; Sadezky et al., 2005).

2.2.3.4. Metamorphic CMs. The CM Raman spectra of major forms of metamorphosed CM (e.g., coal, anthracite, semi graphite and graphite; Fig. 4D) is strongly affected by the solid state formation conditions or recrystallisation of the carbonaceous phase. The structural transformation of organic compounds during catagenesis include the loss of hydrogen and heteroatoms and formation of an increasingly carbon rich residual (Fig. 4D, Table 1; Luque et al., 1998). As metamorphism progresses the carbon atoms are progressively stacked into three-dimensional planar arrays of 6-fold rings/aromatics with progressively decreasing inter-planar distances $\left(\mathrm{d}_{002}\right)$ and the size of the ordered graphite domains $\left(L_{a}\right)$ increases (Luque et al., 1998). The end product is graphite (or semi-graphite). Coalification from peat through bituminous coals and anthracite to graphite is one such natural graphitisation process (Teichmüller, 1986). Corresponding Raman data would show a decreasing D1 peak and an increasing G peak which has been numerically related to crystallite size via a variable scaling coefficient $(C)$ as expressed below:

$\frac{I_{D 1}}{I_{G}}=\frac{C(\lambda)}{L_{a}}$

where $\lambda$ is the excitation wavelength and $L_{a}>2 \mathrm{~nm}$ (Tuinstra and Koenig, 1970).

\subsection{HAADF-STEM, HRTEM and EELS}

Thin foils were cut from Pt coated polished thick sections (equivalent to the polished thin sections used in Raman analysis; CO-24 billet 1; 


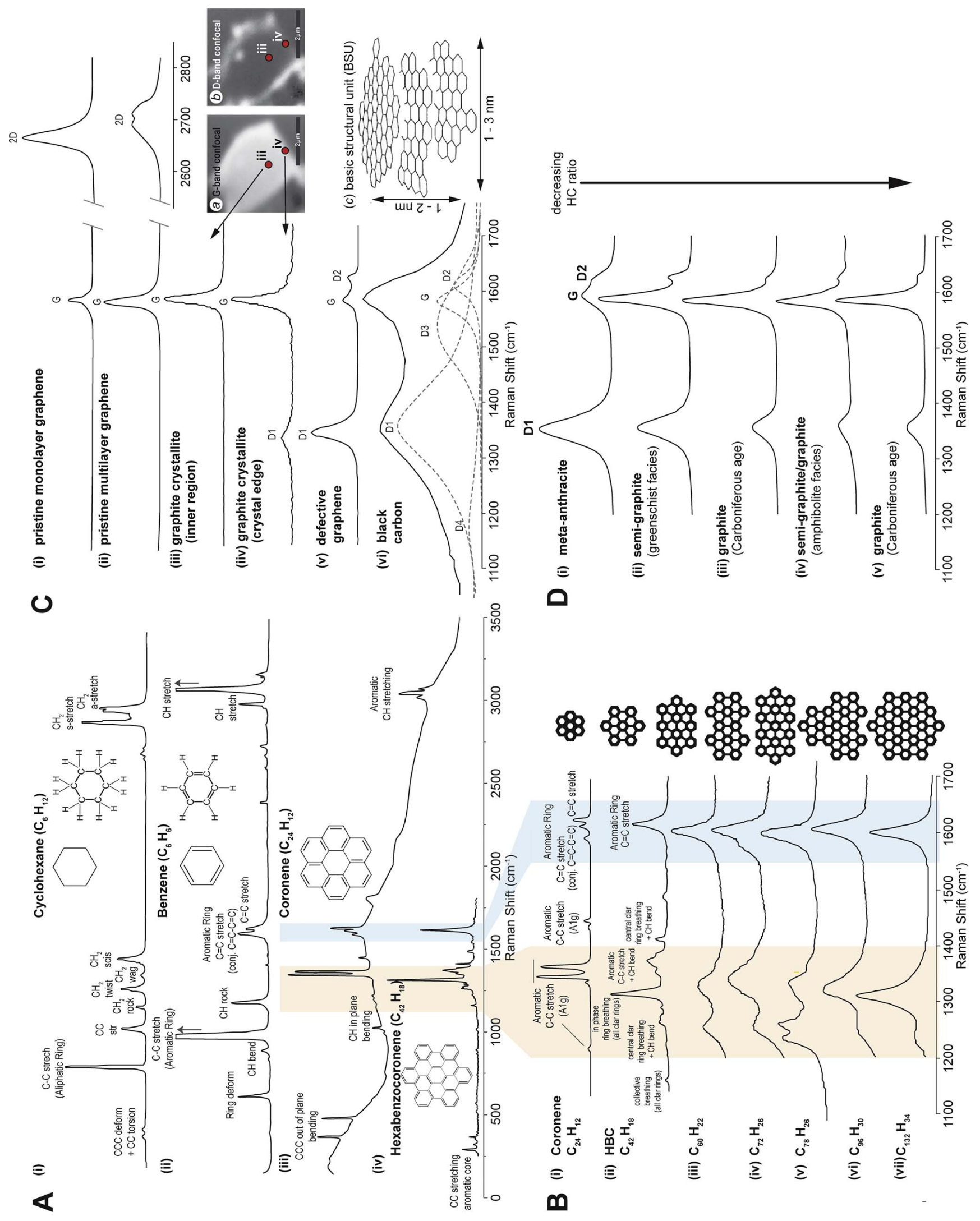




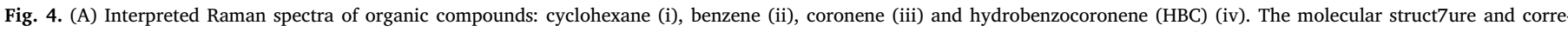

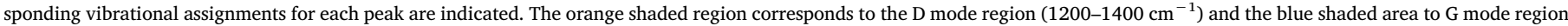

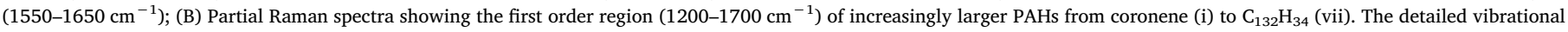

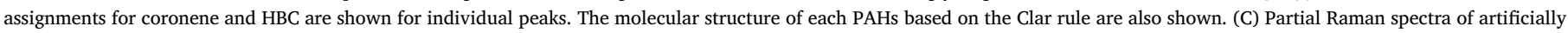

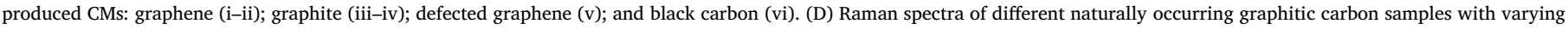

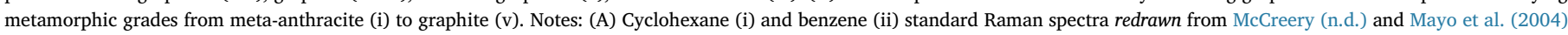

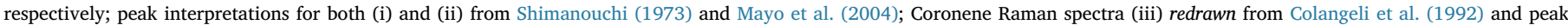

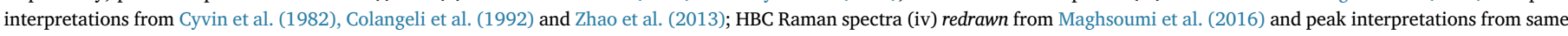

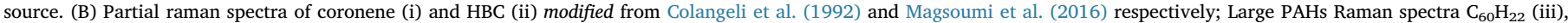

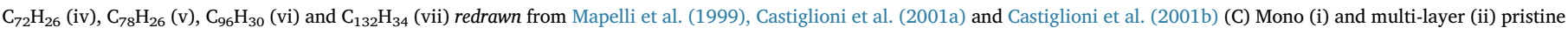

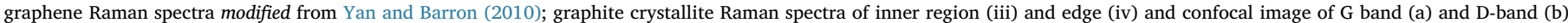

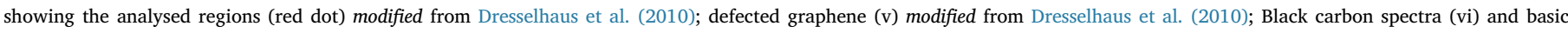

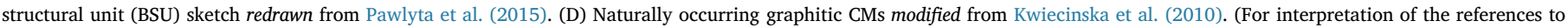
colour in this figure legend, the reader is referred to the web version of this article.)

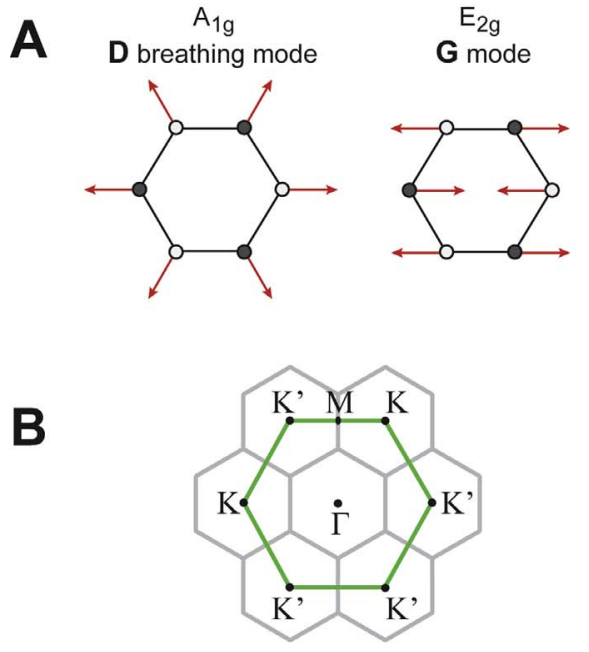

G Band

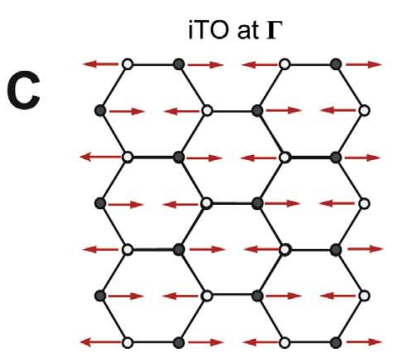

vacancy-type defects edge and sp3-type defects
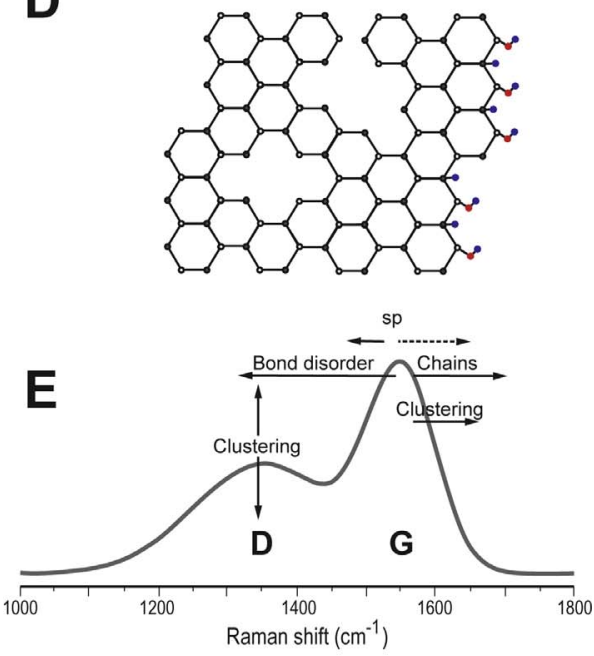

Fig. 5. (A) (left) Carbon motions in the G mode of E2g symmetry, its eigenvector involves the in-plane bondstretching motion of pairs of $\mathrm{C} \mathrm{sp}^{2}$ atoms; (right) carbon motions in the D breathing mode of A1g symmetry involving phonons near the $\mathrm{K}$ zone boundary (modified from Ferrari and Robertson, 2000). (B) Definition of the First Brillouin zone of the two-dimensional graphite (graphene) (in green) showing the centre $\boldsymbol{\Gamma}$, the two inequivalent corners $\mathbf{K}$ and $\mathbf{K}^{\prime}$ (K points) and inequivalent crystallographic points $\mathbf{M}$ (carbon rings are shown in grey) (Reich and Thomsen, 2004). (C) Phonon eigenvectors of graphite: the in-plane longitudinal optic (iLO) and in-plane transverse optic (iTO) phonon modes at $\boldsymbol{\Gamma}$ point; and the D and 2D band in-plane transverse optic (iTO) phonon modes at $\mathbf{K}$ point (redrawn from Beams et al., 2015). (D) Vacancy, edge and $\mathrm{sp}^{3}$ type defects influencing the $\mathrm{D}$ band. Black and white circles for carbon, red and blue circles for oxygen and hydrogen respectively. (E) Factors influencing the primary (D and G) CM bands on the Raman spectra. The dashed arrow marks the indirect influence of the $\mathrm{sp}^{3}$ content on increasing $\mathrm{G}$ position (redrawn from Ferrari and Robertson, 2000). (For interpretation of the references to colour in this figure legend, the reader is referred to the web version of this article.)

Fig. 2A and C) using an FEI Helios Nanolab dual beam focused ion beam scanning electron microscope (FIB-SEM). The corresponding cut off side of CO-24 thin section 1 (i.e., CO-24 billet 1 ) was used for FIB-SEM to avoid the surface damage from the FIB on CO-24 thin section 1, which was simultaneously analysed by Raman spectroscopy. The thin foils were $\mathrm{Pt}$ welded to $\mathrm{Cu}$ grids and polished further to achieve required thickness for subsequent analysis by transmission electron microscopy (TEM) using FEI Titan G2 80-200 TEM/STEM with ChemiSTEM technology operating at $200 \mathrm{kV}$.

HAADF-STEM images and EDS maps were collected from the TEM sample to provide a general overview of the structural and compositional heterogeneity of the sample and identify representative regions for HRTEM and EELS analysis. HRTEM images have been processed using Gatan Microscopy Suite Software. D-spacings have been measured using FFT (fast Fourier transform) patterns generated from HRTEM images.

\subsection{Compound specific Isotopes analyses (CSIA)}

Compound specific isotope analysis (CSIA) was conducted on the HyPy fractions of the parent (Kp) and demineralised (DMK1-3) kerogens available from our previous study (Robert et al., 2016). The $\delta^{13} \mathrm{C}$ values of the major aromatic and selected aliphatic products were measured using a Thermo Scientific Trace gas chromatograph (GC) Ultra interfaced to a Thermo Scientific Delta V Advantage mass

Table 1

Inter-planar distances $\left(\mathrm{d}_{002}\right)$, reflectance $(\% \mathrm{Rmax})$ and $\mathrm{H} / \mathrm{C}$ ratio at different stages of graphitisation.

\begin{tabular}{llcl}
\hline Phase & $\mathrm{d}_{002}$ & \%Rmax & $\mathrm{H} / \mathrm{C}$ \\
\hline Graphite & $3.354-3.37$ & $>9.0$ & $0.005-0.10$ \\
Semi-graphite & $3.37-3.38$ & $6.5-9.0$ & $0.10-0.15$ \\
Meta-anthracite & $3.38-3.40$ & $<6.5$ & $0.15-0.20$ \\
Anthracite & $>3.40$ & $<5.0$ & $\geq 0.20$ \\
\hline
\end{tabular}

Modified from Kwiecinska and Petersen (2004). 
spectrometer via a GC isolink and a Conflo IV. The oxidation furnace consisted of a combustion interface (ceramic tube lined with $\mathrm{NiO}$ and filled with $\mathrm{NiO}$ and $\mathrm{CuO}$ ), which was held at $1000^{\circ} \mathrm{C}$, oxidising GC separated hydrocarbon analytes to $\mathrm{CO}_{2}$. The GC oven was held at $50{ }^{\circ} \mathrm{C}$ for $1 \mathrm{~min}$, increased to $310^{\circ} \mathrm{C}$ at $3{ }^{\circ} \mathrm{C} / \mathrm{min}$, then held isothermally for 20 min. A J\&W Scientific DB-5MS GC column $(60 \mathrm{~m}$ length $\times 0.25 \mathrm{~mm}$ id $\times 0.25 \mu \mathrm{m}$ film) was used with helium as the carrier gas at a constant flow rate of $1 \mathrm{~mL} / \mathrm{min}$. The $\delta^{13} \mathrm{C}$ value of individual compounds was determined by integrating the ion currents of mass 44,45 and 46 and are reported in \%o relative to the international Vienna Pee Dee Belemnite (VPDB) standard. Reported values are the average of at least triplicate measurements with standard deviations usually $<0.5 \%$. Instrument accuracy and precision was monitored on a daily basis using laboratory standards.

\subsection{Total carbon and bulk $\delta^{13} \mathrm{C}$}

To monitor potential compositional and isotopic changes, the parent and all sequentially demineralised kerogen fractions were subjected to total carbon (TC wt\%) and bulk $\delta^{13} \mathrm{C}(\% 0)$ analysis before and after their HyPy treatment. The TC was measured with a Thermo Flush 1112 elemental analyser (EA), using a thermal conductivity detector (TCD; Skrzypek et al., 2006). The TC measurement of the parent kerogen and demineralised fractions includes inorganic carbon. The sequential demineralisation procedure (details in Robert et al., 2016) progressively removes carbonates, and just the HF treated DMK-3 fraction would equate to a traditional TOC measurement.

Bulk $\delta^{13} \mathrm{C}$ was measured using a continuous flow system consisting of a Thermo Flush 1112 EA connected via a Conflo IV interface to a Delta VPlus mass spectrometer (Skrzypek, 2013). All $\delta^{13}$ Cvalues are given in per mil (\%o, VPDB) according to delta notation with standard deviation accuracy of $0.10 \%$.
Table 2

The first order CM Raman bands, observed Raman shift $\left(\mathrm{cm}^{-1}\right)$ and equivalent vibration mode characteristics.

\begin{tabular}{|c|c|c|c|c|}
\hline \multirow{2}{*}{ Band } & \multicolumn{3}{|c|}{ Raman shift } & \multirow{2}{*}{$\begin{array}{l}\text { Vibration mode } \\
\text { Ideal graphitic lattice (E2g-symmetry) }\end{array}$} \\
\hline & 1587 & \pm & 2 & \\
\hline D1 (D) & 1354 & \pm & 3 & $\begin{array}{l}\text { Disordered graphitic lattice (layer edges, A1g } \\
\text { symmetry) }\end{array}$ \\
\hline $\mathrm{D} 2\left(\mathrm{D}^{\prime}\right)$ & 1627 & \pm & 2 & Disordered graphitic lattice (E2g-symmetry) \\
\hline D3 $\left(D^{\prime \prime}\right)$ & 1487 & $\pm \quad 2$ & 27 & Amorphous carbon \\
\hline D4 (I) & 1245 & (fixed) & & $\begin{array}{l}\text { Disordered graphitic lattice (A1g symmetry), } \\
\text { polyenes, ionic impurities }\end{array}$ \\
\hline
\end{tabular}

\section{Results}

\subsection{Laser Raman analysis of $\mathrm{CO}-24$}

A sedimentary transect perpendicular to the sulfide veins (Figs. 2B; 3) was selected for detailed Raman analysis. A combined back scatter (CBS) map of the transect is shown in Fig. 3A. Multiple LR analyses were separately conducted on 11 zones (Z1-Z11; Fig. 3B) representative of the main mineralogical and structural phases evident in the sample. Z1-Z3 were located in the sedimentary matrix; Z4-Z6 were regions of high Na/Fe-mica abundances; Z7-Z9 were within or proximal to the sulfide veins bordered by mica; Z10 was located within the hydrothermal quartz vein; and Z11 was within an arsenopyrite grain proximal to the hydrothermal quartz vein. Twelve EDS maps ( $\boldsymbol{a}-\boldsymbol{l}$; Fig. 3) taken at different locations across the sample transect were also acquired to reflect the distribution of the $\mathrm{CM}$ and associated minerals (Fig. 3C).

\subsubsection{Raman characteristics}

The CM LR spectra consistently showed a number or resolvable bands in two wavelength regimes: 1) the $1000-1800 \mathrm{~cm}^{-1}$ region comprised the first-order discriminative bands G, D1 (D), D2 (D'), D3, and D4; and 2) the $2500-3100 \mathrm{~cm}^{-1}$ region had the second-order bands

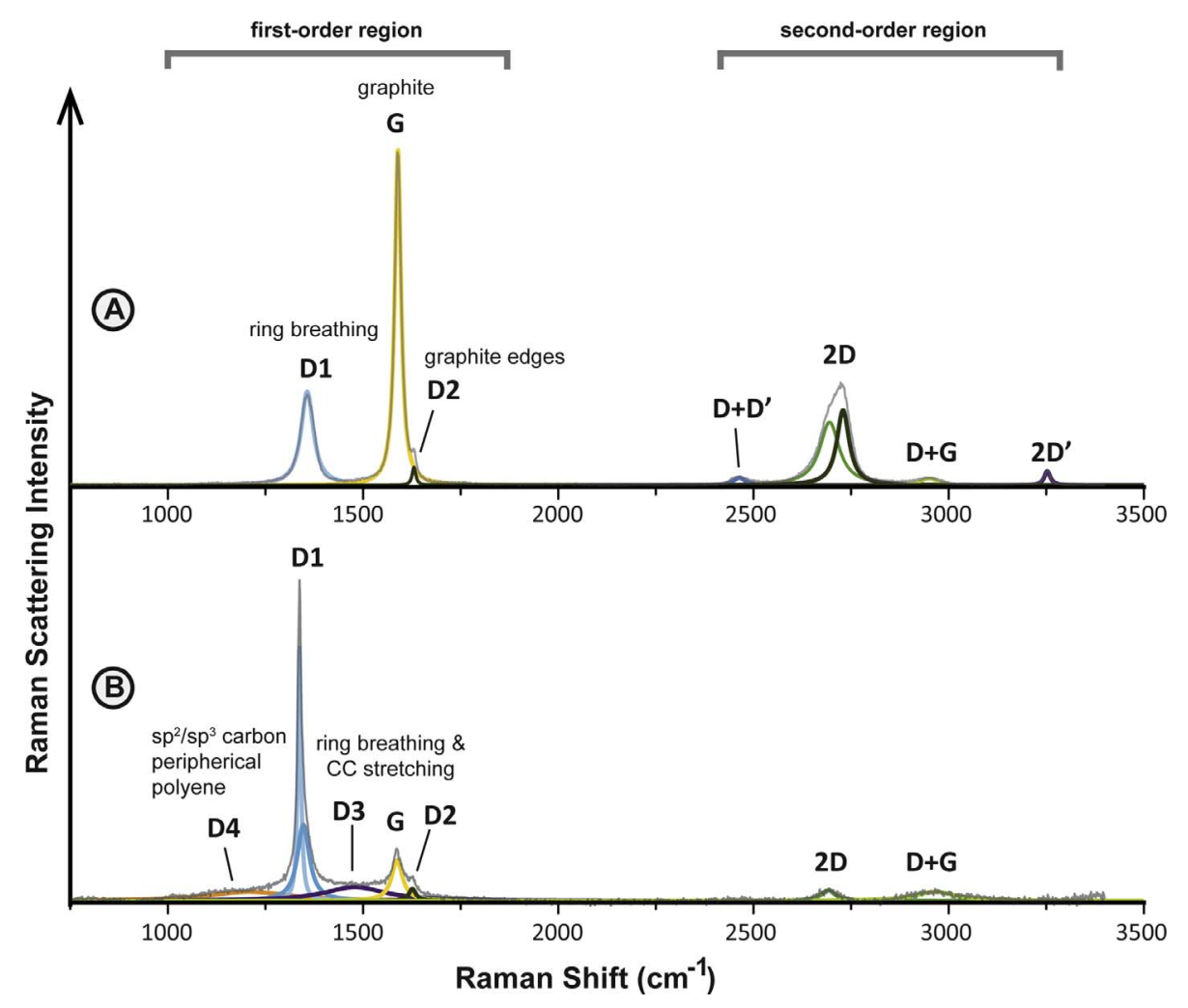

Fig. 6. Laser Raman spectra showing the 1st and 2nd order regions of (A) highly ordered graphite-like CM and (B) highly disordered amorphous-like CM and detailed peak deconvolutions. 
A

Varieties of measured CM Raman spectra in $\mathrm{CO}-24$ thin section 1
B

Equivalent peak decomposition into CM Raman bands

\section{(n)}

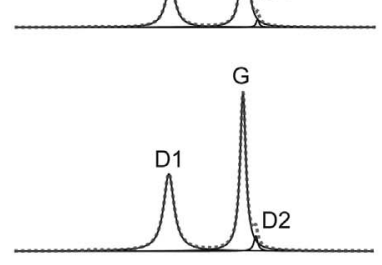

(b)
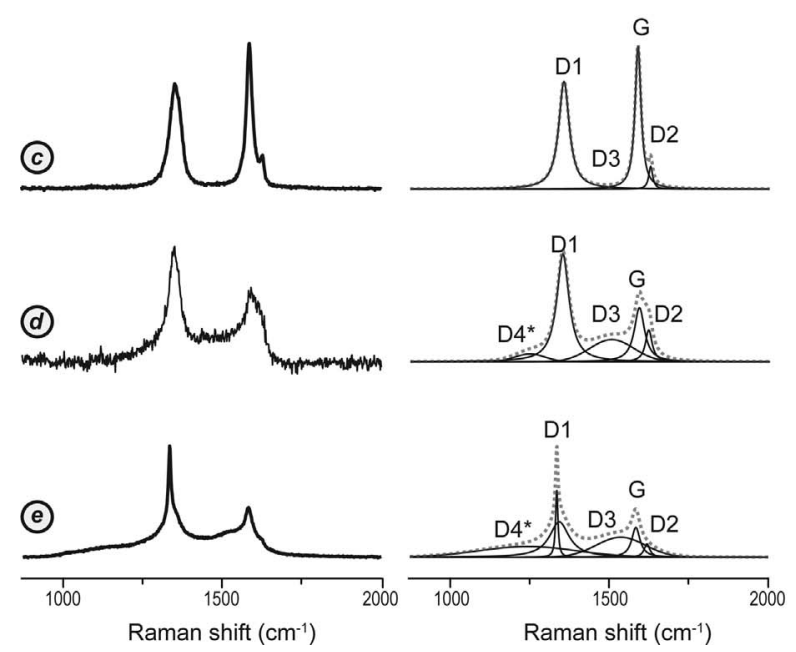

D + D', 2D, D + G, and 2D' that are overtones of the first order bands (Fig. 6) (Beyssac et al., 2002; Bokobza et al., 2013; Wopenka and Pasteris, 1993). The vibration mode characteristics and associated carbon structures of the different CM Raman bands detailed here are summarised in Table 2.

The expanded spectra including the 1st and 2nd order Raman spectral regions of two end member CM's (Fig. 6) show major differences: (A) CM example a from Z2 (Figs. 6A, 7a) show a Raman spectra with bands indicative of a high degree of three-dimensional ordering at 1587 and $2700 \mathrm{~cm}^{-1}$ (prominent G and 2D bands, respectively) and to some extent a degree of disorder with the presence of D1 at $1353 \mathrm{~cm}^{-1}$ and D2 at $1627 \mathrm{~cm}^{-1} .2 \mathrm{D}$ at $2700 \mathrm{~cm}^{-1}$ which is an overtone of the D1 band appears as a partially superimposed doublet that can be resolved into 2 bands (Bokobza et al., 2015, 2013). Other peaks in the second order region include a D + G $\left(2950 \mathrm{~cm}^{-1}\right), \mathrm{D}+\mathrm{D}^{\prime}\left(2465 \mathrm{~cm}^{-1}\right)$ and 2D' $\left(3250 \mathrm{~cm}^{-1}\right)$; on the contrary (B) CM example e from $\mathrm{Z7}$ (Figs. 6B, 7e) show Raman characteristics of a highly disordered CM showing the presence of a $\mathrm{G}$ and $2 \mathrm{D}$ band with a more intensified D1 and D2. Additional disordered Raman bands including D3 $\left(1487 \mathrm{~cm}^{-1}\right)$ and D4 (assigned at $1245 \mathrm{~cm}^{-1}$ ) are also present and only the 2D and D $+\mathrm{G}$ bands were observed in the second order region with very low peak intensity. Whilst the second-order peaks are well-defined for some of the CMs in CO-24 (e.g., Fig. 7a), other CM indicative of highly disordered CMs showed only small modulated bumps between 2300 and $3200 \mathrm{~cm}^{-1}$ (e.g., Fig. 7e). Other intermediate CM signals with strong variations in the first order bands were consistently detected, such as examples $\boldsymbol{b}-\boldsymbol{d}$ shown in Fig. 7.

Raman peaks can be assessed using respective intensity (I) ratio $\mathbf{R} \mathbf{1}$ or area $(A)$ ratio $-\mathbf{R} \mathbf{2}$ of the D and G peaks. The formula for $\mathbf{R} \mathbf{1}$ and R2 ratios (after Rahl et al., 2005) are given as follows:
C

inferred $\mathrm{CM}$

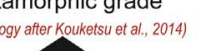

D CM Types

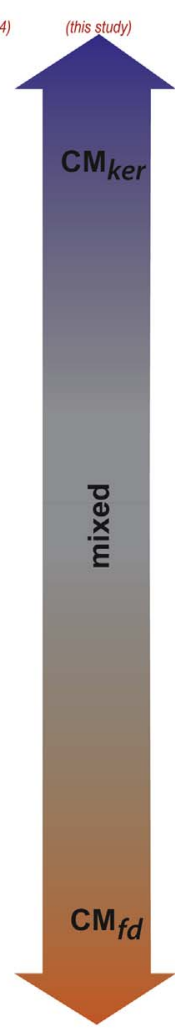

Fig. 7. (A) Selected CM Raman spectra reflecting increasing structural disorder observed from examples $\boldsymbol{a}$ to $\boldsymbol{e}$; (B) Equivalent Gauss-Lorenz decomposition of the Raman spectra into respective bands. The dashed grey lines are the fitted sums and "D4 shift is fixed at $1245 \mathrm{~cm}^{-1}$; (C) metamorphic grade of the selected CMs based on metamorphic sequence identification procedure by Kouketsu et al. (2014); (D) CM type assigned from this study.
$\boldsymbol{R} 1=\frac{I_{D 1}}{I_{G}}$

$\boldsymbol{R} 2=\frac{A_{D 1}}{A_{D 1}+A_{G}+A_{D 2}}$

where $I_{D 1}$ and $I_{G}$ are the peak intensity of the D1 and G band; $A_{D 1}, A_{G}$ and $A_{D 2}$ are the peak areas of the D1, G and D2 bands respectively.

The profiles of different $\mathrm{D}$ and $\mathrm{G}$ band based LR parameters (i.e., R1, R2, $F W H M$ ) across the 11 zones analysed are shown in Fig. 8 and detailed in Table 3A. The sedimentary matrix (Z1-Z6) showed quite consistent Raman signals. However, more variable LR data were obtained in the vein rich regions (Z7-Z11), with Z7 showing the most variability. This large data range reflects different types of carbon structures or CM types. A consistently prominent D band $\left(\boldsymbol{I}_{D 1}>\boldsymbol{I}_{G}\right)$ translated to quite high and wide ranging values of R1 (1.5-8) and R2 (0.5-0.8). Some analyses showed $\mathrm{G}$ band broadening (i.e., $>\mathrm{G}_{F W H M}$ ), which may be due to greater bond disorder, a clustering of aromatic units (Fig. 5E) or the presence of straight chain compounds (Ferrari and Robertson, 2000).

An R2 vs. R1 plot of the Raman data is shown in Fig. 9A and their spatial distribution across the thin section transect in Fig. 9B. The R2 vs. R1 data profile suggests a progression of CM types from a highly disordered CM to highly crystalline graphite (Fig. 9A) based on the scheme outlined by Kouketsu et al. (2014). Characteristics of each of the CM groups were: (i) Group 1 (Fig. 6a and b) - prominent G peak, indicative of well-crystallised graphite; clearly recognizable D1 and D2 peaks and R1 < 0.5; no D3 and D4 bands; (ii) Group 2 (Fig. 6c and d) $0.5 \geq \mathrm{R} 1<1.5$; distinguishable D3 or D4 bands; and (iii) Group 3 (Fig. 6e) - an unusually intense D1 band, presence of D3 or D4 bands typical of amorphous C; $(\mathrm{R} 1 \geq 1.5)$. Fig. 9B shows the spatial distribution of the $\mathrm{CM}$ groups and their different mineralogical and 


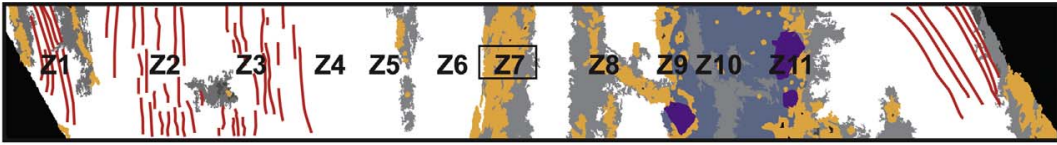

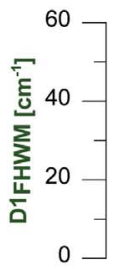
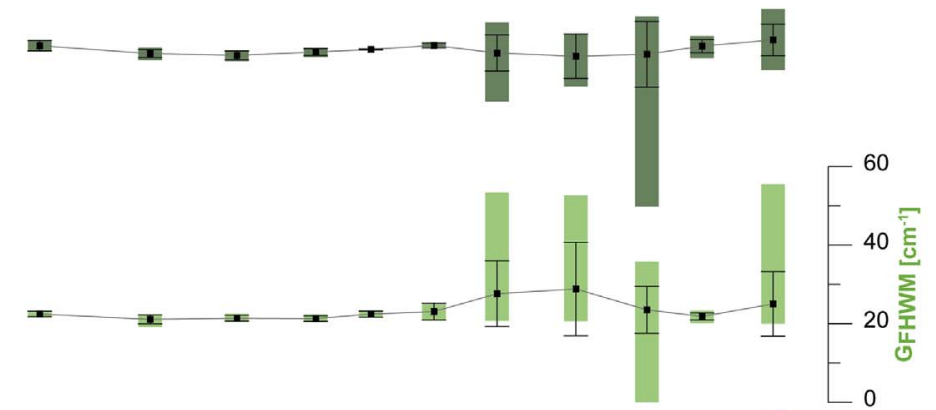

㲾 $20-$
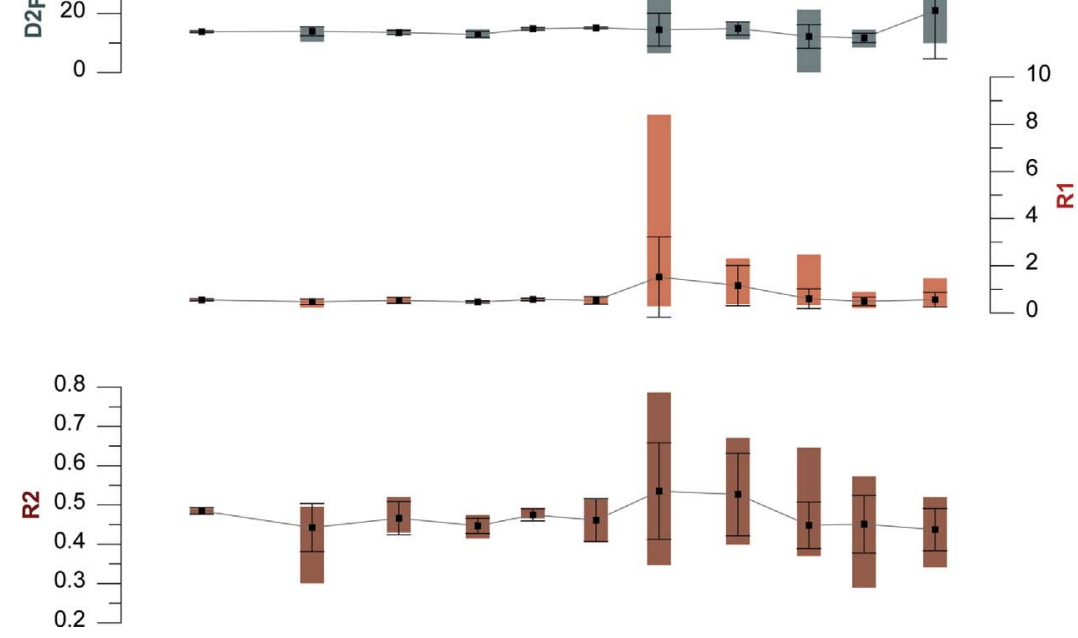

Fig. 8. Value range of $D$ and $G$ band parameters (e.g., FWHM, intensity ratio - R1, area ratio - R2), across analysed zones by Raman spectroscopy. Coloured solid rectangles show the range of values covering the minimum and maximum values of measurements, solid black squares are the average values of measurements; the standard deviation of values are also shown. structural affinities. CM Groups 1 (blue data points) and 2 (grey data points) were detected ubiquitously across the transect (Z1-Z11). Group 2 was notably more abundant in the zones corresponding to the sulfide veins (Z7-Z11), which is also where all the Group $3 \mathrm{CM}$ (orange data points) were detected. Group 3 signals were constrained also within sulfide minerals such as pyrite and arsenopyrite and found along intermineral boundaries.

\subsubsection{Raman spectral comparison of pre- and post-HyPy DMK-3}

The HyPy treatment of DMK-3 led to lower R1 and R2. Pre-HyPy $\mathbf{R} \mathbf{1}=0.36$ and $\mathbf{R 2}=0.40$ whereas post-HyPy $\mathbf{R} \mathbf{1}=0.30$ and $\mathbf{R 2}=0.36$ (Table 3B), consistent with the successful HyPy isolation of the graphite like black $\mathrm{C}$ fraction of sedimentary $\mathrm{CM}$ as previously demonstrated by others (Ascough et al., 2009). The D2 $2_{F W H M}$ also observed to decrease significantly from a pre-HyPy average value of 22 compared to post-HyPy average value of 16 . This decrease may be signifying the HyPy release of PAHs present at the edges of the graphite moieties.

\subsection{Nanoscale CM characterisation - EELS, STEM and HRTEM}

The nano-structural analysis of CO-24 identified only two distinct CM types: (1) a highly graphitic, crystalline CM (Fig. 10B-1) with interC layer spacing values $\left(\mathrm{d}_{002}\right)$ of $\sim 3.350 \AA$ (Fig. $11 \mathrm{~B}-1$ \& 2 ); and (2) a highly disordered, amorphous CM rich in PAHs (Figs. 10B-2, 11B-3).

The EELS spectrum image from the TEM analysed sample is shown in Fig. 10A. This sample was taken from the equivalent region between Z6 and Z7 (Fig. 2) representing the sedimentary matrix and sulfide veins boundary. Spectra indicative of the (1) highly graphitic and (2) highly disordered amorphous carbon signals are shown in Fig. 10B. These CM were assigned based on nano-scale characteristics and the spectra of standard C allotropes reported by Garvie et al. (1994) that are reproduced in Fig. 10C for comparison. They were the only two types of CM detected and were each distributed broadly throughout the sample analysed.

The HAADF-STEM image of the same sample is shown in Fig. 11A along with extracted EDS from three morphologically distinctive parts $(a, b, c)$ showing elemental composition. These correspond to $(a)$ white regions consisting of $\mathrm{Fe} / \mathrm{Mg}$-rich mica with negligible carbon; (b) dark nodules within the mica, which contains mixed mica and carbon signals, and also relatively low $\mathrm{Si}$ and $\mathrm{O}$ signals from the micaceous background; and (c) grey areas, which are pure carbon.

The HRTEM image of the black rectangular zone in Fig. 11A is shown in Fig. 11B. Here, the grey C areas of the STEM image are revealed to comprise relatively symmetrical carbon structures. C-atomic planes with a striking pseudo-parallel (graphite like) arrangement are clearly visible in the zoomed areas 1 and 2 . The Fast Fourier Transform (FFT) patterns of the 1 and 2 areas indicate a high degree of (graphitic) crystallinity and inter-layer spacing values $\left(\mathrm{d}_{002}\right)$ of $3.350 \AA$ and $3.346 \AA$, respectively (Fig. 11B-1 \& 2).

The small specks of $\mathrm{C}$ ubiquitous within the mica regions show a very different structural morphology (zoomed area 3). Their HRTEM 


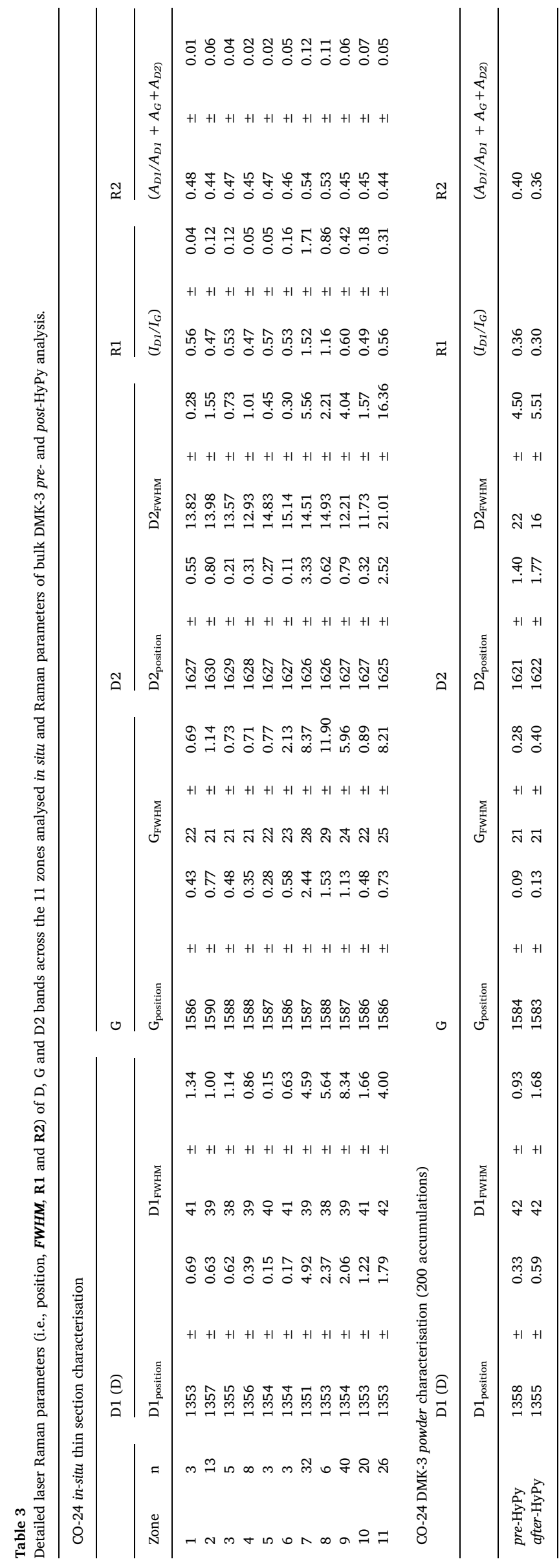

image reveals a highly-disordered amorphous structure (Figs. 10B2, 11B-3). The surrounding micaceous host had highly-disordered $\mathrm{C}$ with an inter-layer spacing $\left(\mathrm{d}_{002}\right)$ of $0.24 \AA$, that is much smaller than graphite. The contact zones of the graphitic C and mica (Fig. 11B, indicated by black arrows) also show a concentration of highly disordered $\mathrm{CM}$ similar to those found in the $\mathrm{C}$ nodules.

\subsection{Stable carbon isotope analysis of kerogen samples}

3.3.1. Parent and demineralised kerogens - Bulk and compounds specific $\delta^{13} \mathrm{C}$ data

The $\delta^{13} \mathrm{C}$ values of bulk kerogens measured by elemental analysis isotope ratio mass spectrometry (EA-irMS) and the most abundant HyPy products of the parent (Kp) and demineralised kerogen (DMK-1-3) fractions measured by GC-irMS are given in Table $4 . \delta^{13} \mathrm{C}$ values of pyrene, di- and tetrahydropyrene and some larger PAHs (e.g., tetracosahydrocoronene and coronene) were measured for most samples. The $\delta^{13} \mathrm{C}$ profile of the parent and hydrogenated pyrenes in relation to their HyPy concentrations following sequential demineralisation is shown in Fig. 12.

The pyrene released by HyPy treatment of the native kerogen (Kp) had a ${ }^{13} \mathrm{C}$ value $-17.3 \%$. With each demineralisation step pyrene became progressively depleted in $\delta^{13} \mathrm{C}$ with values of $-19.9 \%$, $-23.0 \% 0$ and $-31.2 \%$ from DMK1-3, respectively. The hydrogenated pyrenes were slightly more depleted than pyrene $\left(\Delta^{13} \mathrm{C}_{\mathrm{Py}}\right.$ $2 \mathrm{HPy}=0.6-1.3 \%$; and $\Delta{ }^{13} \mathrm{C}_{\mathrm{Py}-4 \mathrm{HPy}} \sim 2 \%$ except for DMK-3 where it was $-0.8 \%$ ), but showed a similar trend of greater ${ }^{13} \mathrm{C}$ depletion with demineralisation. A catalytic effect from the high pyrite content of the sediments may contribute to the lighter $\delta^{13} \mathrm{C}$ values of the hydrogenated pyrenes. A similar ${ }^{13} \mathrm{C}$ depletion with demineralisation was reflected by the hydrogenated products of other PAHs (e.g., coronene), and we previously observed a similar trend where hydrogenated products of pure PAH standards treated by HyPy had lighter $\delta^{13} \mathrm{C}$ values than the parent aromatic (Grotheer et al., 2015). The $\delta^{13} \mathrm{C}$ values of $n$ alkanes released on HyPy treatment of the demineralised kerogens (DMK1-3) were -27 to $-28 \%$ o (Table 4 ). No alkanes were detected from Kp.

\subsubsection{Bulk $\delta^{13} \mathrm{C}$ of kerogens - pre- and post-HyPy}

The $\delta^{13} \mathrm{C}$ value of the parent kerogen (Kp) was $-6.7 \%$, indicative of a mixed organic carbon and carbonate signal. Coexisting carbonate veins had $\delta^{13} \mathrm{C}$ values near $0.6 \%$ whilst the demineralised kerogens (DMK-1 to -3) were consistently measured to be $-27 \%$ typical of organic biopolymeric material. Following HyPy treatment the parent and demineralised kerogen all had $\delta^{13} \mathrm{C}$ values of $-27.6 \%$. DMK-2 gave the largest HyPy product yields as reflected by the concentration profiles of pyrene products from the demineralised kerogens (Fig. 12).

\section{Discussions}

\subsection{CM types in CO-24 - Raman based vs. Nanoscale interpretation and its source}

Variances in the first order bands have traditionally been used to distinguish different CM types (e.g., Wopenka and Pasteris, 1993; Cuesta et al., 1994; Beyssac et al., 2002, 2003; Rahl et al., 2005; Sadezky et al., 2005; Kouketsu et al., 2014), and here imply a range of different CM types in CO-24 (Fig. 7) that can be correlated to metamorphic grades. Kouketsu et al. (2014) proposed a Raman based classification scheme to characterise $\mathrm{CM}$ of different metamorphic grades comparable to those reported by Beyssac et al. (2002) and Rahl et al. (2005). The application of this organised scheme to the Raman data of CO-24 suggests the occurrence of three $\mathrm{CM}$ groups and their equivalent metamorphic grades:

Group 1 - High grade CM (Fig. 6a and b): R1 < 0.5; prominent G peak, indicative of well-crystallised graphite; clearly recognizable D1 

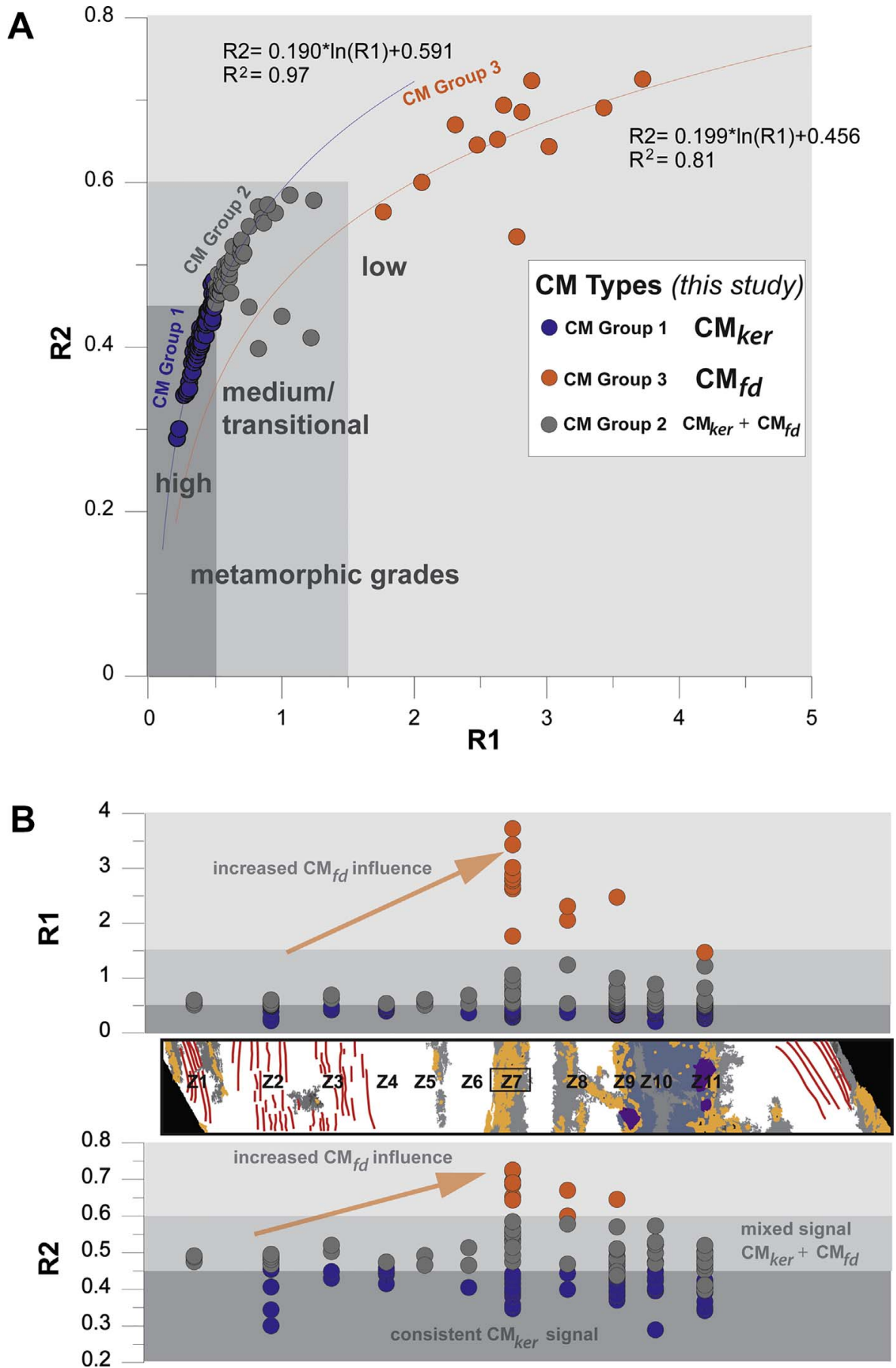

Fig. 9. (A) Laser Raman R1 vs. R2 distribution of CM. The measured values follow a logarithmic trend with metamorphic groups assigned based on value ranges suggested by Beyssac et al. (2003) and application of the metamorphic scheme proposed by Kouketsu et al. (2014): Group 1 (blue circles; R1 < 0.5; R2 < 0.45) had values indicative of a high metamorphic grade $\mathrm{CM}$, Group 2 (grey circles; $0.5 \geq \mathbf{R} 1<1.5 ; 0.45 \geq \mathbf{R} 2<0.6$ ) were indicative of a medium/transitional metamorphic grade CM; and Group 3 (orange circles; $\mathbf{R} 1 \geq 1.5 ; \mathbf{R} 2 \geq 0.6$ ) fitted a low metamorphic grade CM; (B) The spatial representation of the three groups defined in A across the transect zones. (For interpretation of the references to colour in this figure legend, the reader is referred to the web version of this article.) and D2 peaks and; no D3 and D4 bands.

Group 2 - Medium grade CM (Fig. $6 \mathrm{c}$ and d): $0.5 \geq \mathbf{R} 1<1.5$; D and G bands of generally similar intensity; distinguishable D3 and/or D4 bands.

Group 3 - Low grade CM (Fig. 6e): $\mathbf{R} 1 \geq 1.5$; an unusually intense D1 band, presence of D3 and/or D4 bands typical of amorphous C.

These 3 groups are well resolved by the $\mathbf{R} \mathbf{2} v s$. R1 plot of the Raman data shown in Fig. 9A and their spatial distribution across the thin section transect is shown in Fig. 9B. Following the scheme outlined by Kouketsu et al. (2014). This data suggests a progression of CM types from a low to high metamorphic grade. However, the co-occurrence of such a localised variety of $\mathrm{CM}$ types (i.e., within a $20 \mathrm{~mm}$ transect) would seem surprising given the high regional stresses and contact metamorphism of the orogenic Au deposit. In contrast to the Raman analysis suggesting CM types of highly varying metamorphic grade in CO-24, the micro-imaging techniques morphologically distinguish only 2 types of $\mathrm{CM}$ which we refer to as:

$\mathbf{C M}_{\text {ker }}$ - corresponding to a highly graphitic, crystalline CM (Fig. 10B-1) with inter-C layer spacing values $\left(\mathrm{d}_{002}\right)$ of $\sim 3.350 \AA$ (Fig. 11B-1 \& 2), which represents regional kerogen subjected to syngenetic graphitisation (discussed in detail in 4.1.1).

$\mathbf{C M}_{f d}$ - equivalent to highly disordered, amorphous CM (Figs. 10B2, 11B-3) rich in PAHs, which we attribute to a hydrothermal fluid deposited (FD) source (discussed in detail in 4.1.2).

These CMs may have derived from similar sources and formed by different geological processes. The spatial distribution of $\mathbf{C M}_{\boldsymbol{k e r}}$ and $\mathbf{C M}_{\boldsymbol{f} d}$ through the sediment may be responsible for the variations evident in the Raman analysis. 


\section{A. EELS Spectrum image}

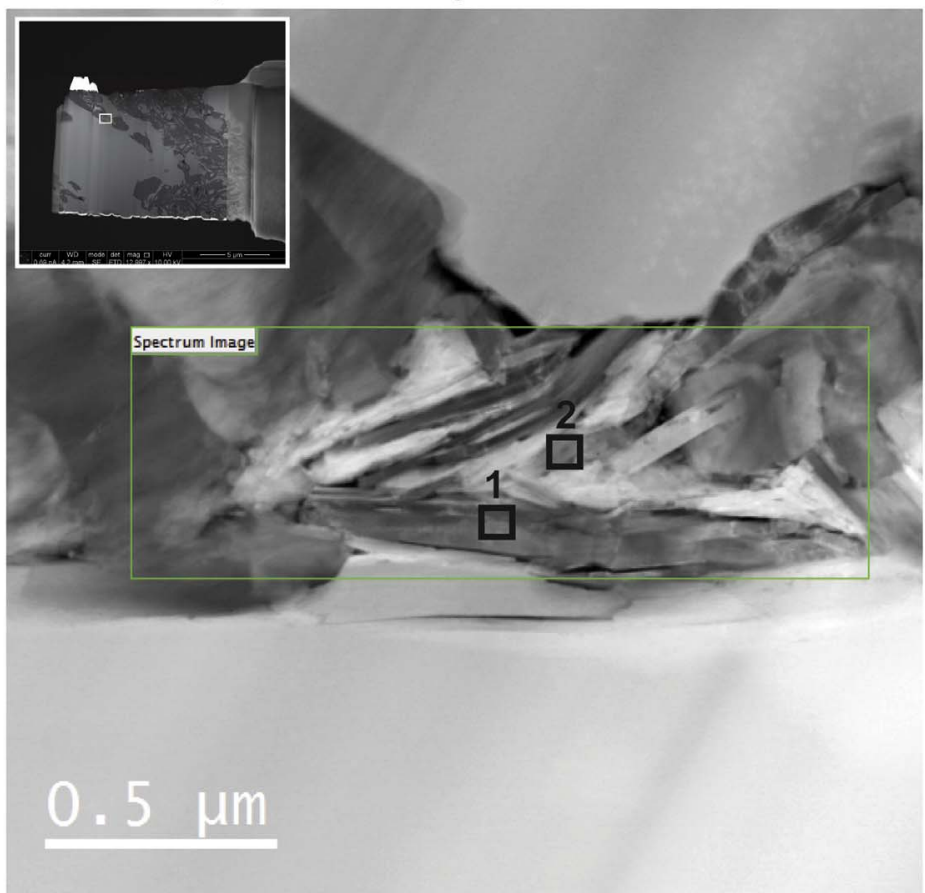

Fig. 10. (A) EELS spectrum image of a selected area from the TEM section taken from the sedimentary matrix; rectangular region upper left of the image shows the TEM section with the selected area (white rectangle) highlighted; (B) EELS spectra of (1) graphitic CM and (2) amorphous (highly disordered) carbon signal, respectively; the EELS extracted (black rectangle) regions (1) and (2) are shown in (A); (C) C K edge from minerals (EELS) containing three allotropes of $\mathrm{C}$ (diamond, graphite and amorphous $\mathrm{C}$ ) and common C anion (calcite, siderite) (modified from Garvie et al., 1994).

\section{B. Extracted EELS spectrum}
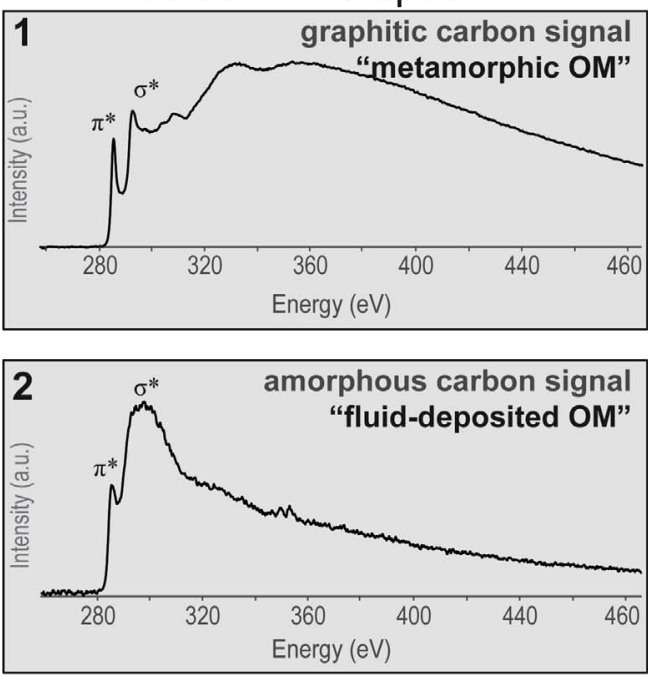

C. $C K$ edge of $C$ materials

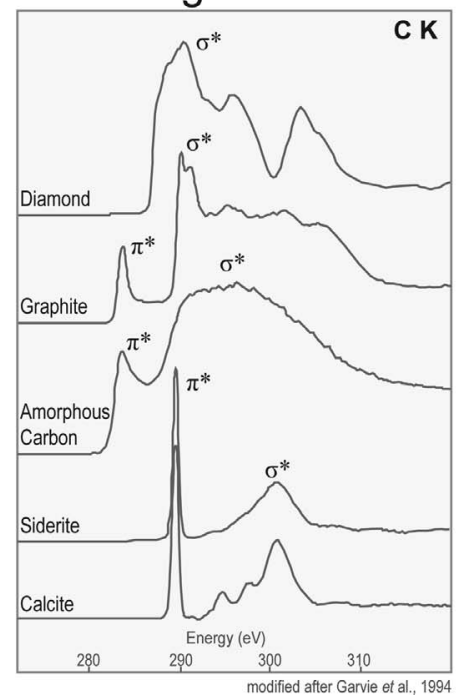

\subsubsection{Metamorphic transformation of syndepositional OM into kerogen} $\left(C M_{k e r}\right)$

$\mathbf{C M}_{\text {ker }}$ was the most prevalent morphology detected in CO-24 by nano-imaging and likely represents regional kerogen subjected to syngenetic graphitisation caused by the extreme metamorphic conditions. Inter-planar distances measurable by HRTEM provide the only reliable distinction between CM at different stages of graphitisation (Table 1; Kwiecinska and Petersen, 2004). The $\mathrm{d}_{002}$ of pure graphite $=3.35 \AA$ and its $L_{a}$ is at least $10^{2}-10^{3} \AA$. Much of the highly-ordered CM observed in CO-24 reflects such crystallinity. The $\mathrm{d}_{002}$ values of the two highly ordered CM regions evident in Fig. 11 have $d_{002}$ values of $3.350 \AA$ and $3.346 \AA$ respectively. These C-structures are typical of syngenetic kerogen exposed to high (regional and contact) metamorphic conditions.

The metamorphic conditions of the Koolpin Formation (host for the Cosmo Howley deposit) arose from complex and multiple deformation events before and following the intrusion of the Cullen Batholith
(1835-1825 MYA) (Ewers et al., 1985; Needham et al., 1988; Bajwah, 1994; Matthäi et al., 1995a; Matthäi and Henley, 1996; Partington and McNaughton, 1997). These events could have influenced the transformation of the in situ kerogen to the presently observed highly graphitic $\mathbf{C M}_{\text {ker }}$. Kerogen usually has the form of finely dispersed particulate organic matter in sedimentary rocks, with a 'random (geo)polymer-like' macromolecular structure that is relatively immobile following deposition (Mossman, 1999). This immobility would have exposed it to the regional geological events of the Cosmo Howley deposit.

The $\mathbf{C M}_{\text {ker }}$ in CO-24 likely corresponds to the Raman CM Group 1, which were essentially ubiquitous across the transect gradient analysed (blue points in Fig. 9). $\mathbf{C M}_{\text {ker }}$ is likely organic in nature, given the black (or graphitic) C isolates from the HyPy treatments of the parent and demineralised kerogens consistently had $\delta^{13} \mathrm{C}$ values of $-27.6 \%$. This value is consistent with the predominantly microbial (i.e., algae, bacteria) sources of OM during the Paleoproterozoic. 
A. STEM image and composition
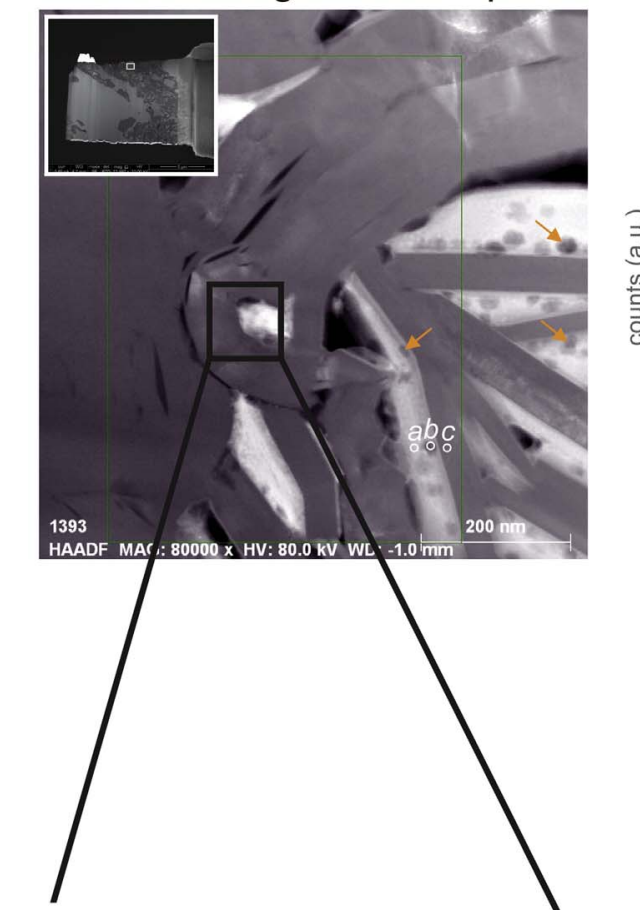

B. HRTEM image and FFT

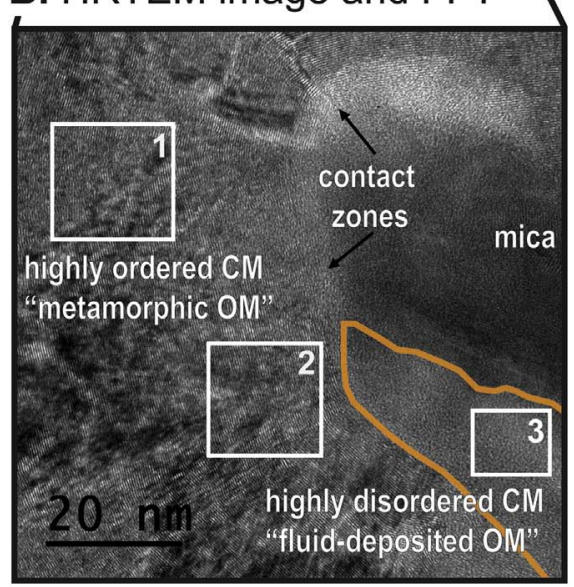

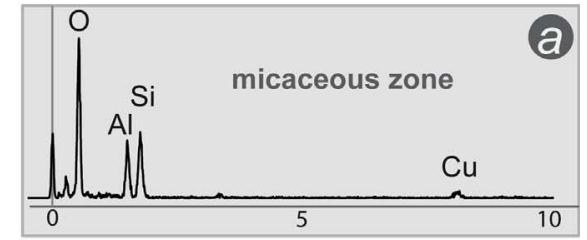
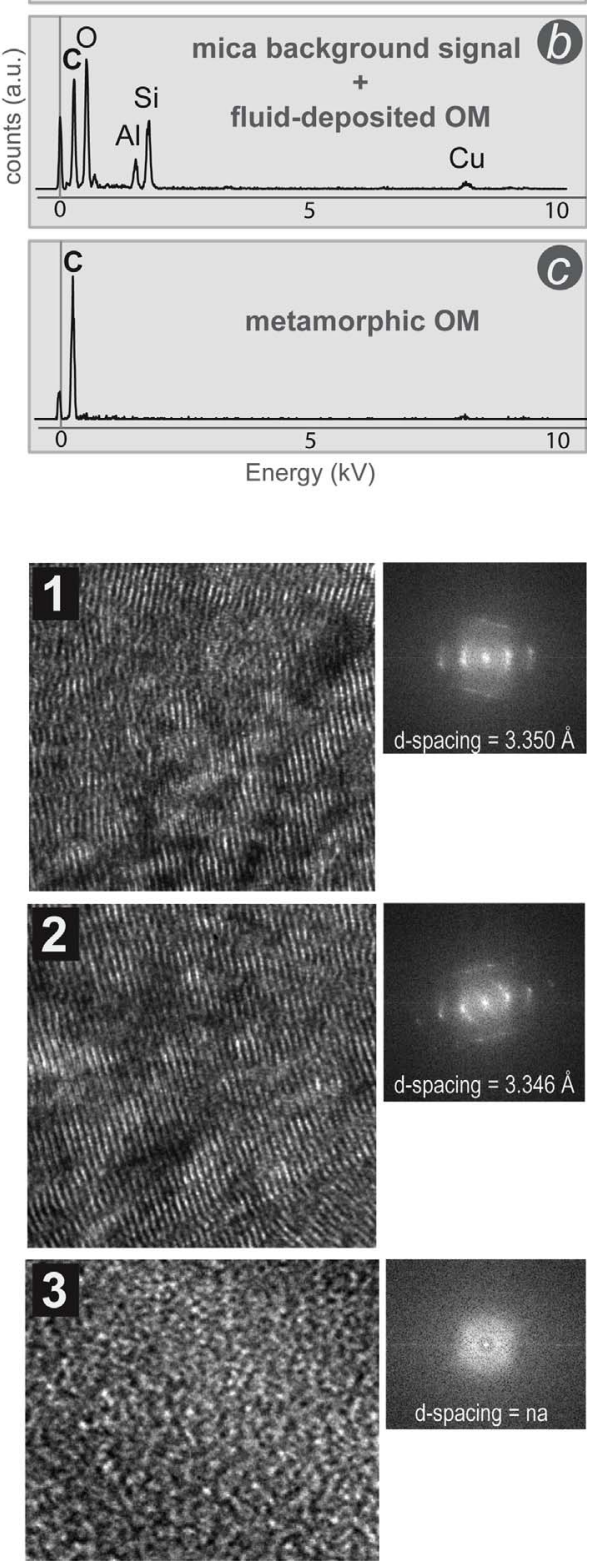

Fig. 11. (A) HAADF-STEM image showing the medium grey $\mathrm{CM}$ zones $\left(\mathbf{C M}_{\text {ker }}\right)$. White regions are the mica and dark grey $\mathrm{CM}$ nodules and lenses $\left(\mathbf{C M}_{f d}\right)$. Extracted EDS spectra of these regions are shown on the right $(a)$ micaceous zone; $(b)$ background mica $+\mathbf{C M}_{f d}$; and (c) $\mathbf{C M}_{\text {ker }}$; (B) HRTEM image of the black rectangular region in (A); zoom of white rectangular regions 1,2 , and 3 (centre); and equivalent processed FFT patterns of these areas (right) are also shown. The contact zones of the highly ordered $\mathrm{CM}\left(\mathbf{C M}_{k e r}\right)$ and mica are indicated by the arrows; the orange trace shows the disordered $\mathrm{CM}\left(\mathbf{C M}_{f d}\right)$ region. (For interpretation of the references to colour in this figure legend, the reader is referred to the web version of this article.)

\subsubsection{Hydrothermal fluid deposited PAHs rich $O M-\mathbf{C M}_{\boldsymbol{f d}}$}

Highly disordered amorphous carbons (i.e., $\mathbf{C M}_{f d}$ ) were additionally detected by the nanoscale imaging of CO-24 sample - The primary BSUs components (molecularly defined graphitic clusters) of these amorphous carbons are made up of turbostacked PAH units that are also present in defective CMs (Castiglioni et al., 2001b). Thus, the elevated intensity of the D1 peak signal from amorphous carbons mainly represents the concentration of 6-fold rings (i.e., aromatics) in the laser excited region (Ferrari and Robertson, 2000).

As discussed in Section 4.1, the D band is activated only within a small region of the crystal (i.e., the edge of the molecular structure or in defected regions). In contrast to the continuous aromatic sheets of graphite or graphene, the BSUs of amorphous carbons includes PAH clusters of small crystallite size $\left(L_{a}<2 \mathrm{~nm}\right)$ and depending on the quantity of BSUs present, may contain a higher proportion of the structural edges and defects and consequently a high intensity D1 peak (Nb., the max size of BSUs is $3 \times 3 \times 2 \mathrm{~nm}$, so possibly hundreds of BSUs could occur within the Raman laser spot region of $300 \mathrm{~nm}$; for a perfect graphite crystal of $1 \mu \mathrm{m}$, the Raman laser spot may be focused on the central part of the crystal without any interference from the structural edge). Therefore, a D1 peak develops with the increased concentration of BSU containing PAHs (Casiraghi et al., 2005; Ferrari and Robertson, 2000) in the laser irradiated/analysed zone and is expressed by the proportionality:

$\frac{I_{D 1}}{I_{G}} \propto M$

where $M$ is the number of 6-fold rings/aromatics (Ferrari and Robertson, 2000). 
Table 4

$\delta^{13} \mathrm{C}$ values for the parent (Kp) and demineralised kerogen (DMK-1-3) fractions of: HyPy released hydrocarbon compounds (top); and bulk kerogens, along with TC\% (bottom).

\begin{tabular}{|c|c|c|c|c|c|c|c|c|c|c|c|c|c|}
\hline \multicolumn{2}{|c|}{ CO-24 MC HyPy CSIA [\%o VPDB] } & \multicolumn{3}{|l|}{ Kр } & \multicolumn{3}{|l|}{ DMK-1 } & \multicolumn{3}{|l|}{ DMK-2 } & \multicolumn{3}{|l|}{ DMK-3 } \\
\hline \multicolumn{14}{|c|}{ Aromatic fraction } \\
\hline \multirow[t]{6}{*}{ Pyrene Group } & 10H-Pyrene A & & & & & & & -23.7 & \pm & 0.2 & & & \\
\hline & 4H-Pyrene & -19.4 & \pm & 0.0 & -22.3 & \pm & 0.1 & -25.1 & \pm & 0.1 & -30.4 & \pm & 0.2 \\
\hline & $6 \mathrm{H}$-Pyrene A & & & & -21.1 & \pm & 0.1 & & & & & & \\
\hline & 6H-Pyrene B & & & & -20.9 & \pm & 0.1 & -24.0 & \pm & 0.4 & & & \\
\hline & 2H-Pyrene & -18.0 & \pm & 0.2 & -20.7 & \pm & 0.2 & -23.5 & \pm & 0.1 & -32.5 & \pm & 0.1 \\
\hline & Pyrene & -17.3 & \pm & 1.1 & -19.9 & \pm & 0.1 & -23.0 & \pm & 0.1 & -31.2 & \pm & 0.3 \\
\hline \multicolumn{2}{|c|}{ Total Pyrene Yield (ng/g TOC) } & 854 & & & 2578 & & & 8296 & & & 9465 & & \\
\hline \multirow[t]{4}{*}{ other PAHs } & 2-Methylpyrene & & & & & & & & & & -25.0 & \pm & 0.1 \\
\hline & 4-Methylpyrene & & & & & & & & & & -27.9 & \pm & 0.2 \\
\hline & Benzo[ghi]perylene & -26.5 & \pm & 0.2 & & & & & & & & & \\
\hline & Coronene & -24.9 & \pm & 0.1 & & & & & & & & & \\
\hline \multicolumn{14}{|c|}{ Aliphatic fraction } \\
\hline & Tetracosahydrocoronene & -28.0 & \pm & 0.2 & & & & & & & & & \\
\hline \multirow[t]{3}{*}{ n-alkanes } & $n-C 18$ & & & & -26.7 & \pm & 0.2 & & & & -27.2 & \pm & 0.2 \\
\hline & $n-C 2 O$ & & & & & & & -28.4 & \pm & 0.1 & -27.8 & \pm & 0.6 \\
\hline & $n-C 22$ & & & & -27.9 & \pm & 0.3 & -27.4 & \pm & 0.0 & -27.2 & \pm & 0.5 \\
\hline \multicolumn{2}{|c|}{ Total n-alkane Yield (ng/g TOC) } & 0 & & & 1720 & & & 514 & & & 2750 & & \\
\hline \multicolumn{2}{|c|}{ CO-24 MC HyPy Bulk $\delta^{13} \mathrm{C}$ [\%。 VPDB] } & Kp & & & DMK-1 & & & DMK-2 & & & DMK-3 & & \\
\hline \multicolumn{14}{|l|}{ Pre-HyPy } \\
\hline & Total Carbon wt.\% & 13.3 & \pm & 0.1 & 16.7 & \pm & 0.1 & 24 & \pm & 0.1 & 32.5 & \pm & 0.1 \\
\hline & Bulk $\delta^{13} \mathrm{C}[\%$ VPDB] & -6.7 & \pm & 0.1 & -26.9 & \pm & 0.1 & -27.4 & \pm & 0.1 & -26.9 & \pm & 0.1 \\
\hline \multicolumn{14}{|c|}{ After-HyPy Residue } \\
\hline & Total Carbon wt.\% & 16.7 & \pm & 0.1 & 19.7 & \pm & 0.1 & 20.3 & \pm & 0.1 & 32.2 & \pm & 0.1 \\
\hline & Bulk $\delta^{13} \mathrm{C}[\%$ VPDB] & -27.62 & \pm & 0.1 & -27.52 & \pm & 0.1 & -27.73 & \pm & 0.1 & -27.5 & \pm & 0.1 \\
\hline
\end{tabular}

Hence, the intense D1 peak observed for Group 3 CMs identified by Raman analysis ( $\mathbf{R} 1 \geq 1.5$, orange data points, Fig. 9A \& B) is representative of the relatively high abundance of PAH structural moieties of $\mathbf{C M}_{f d}$. Furthermore, this suggests that the PAHs released in relatively high abundances by HyPy treatment derive from the amorphous $\mathbf{C M}_{\boldsymbol{f d}}$. Conversely, the HyPy residual fraction most likely equates to $\mathbf{C M}_{\text {ker }}$ which Raman analysis showed has a graphitic like structure.

The D3 and D4 peaks observed in Group 3 CM (Fig. 7e) are common to the Raman spectra of amorphous or defective carbons (e.g., black carbon, soot and coal; Fig. 4C-vi). These peaks and equivalent alkane vibrational modes within this Raman region (i.e., $\mathrm{CH}_{3} / \mathrm{CH}_{2}$ deform at

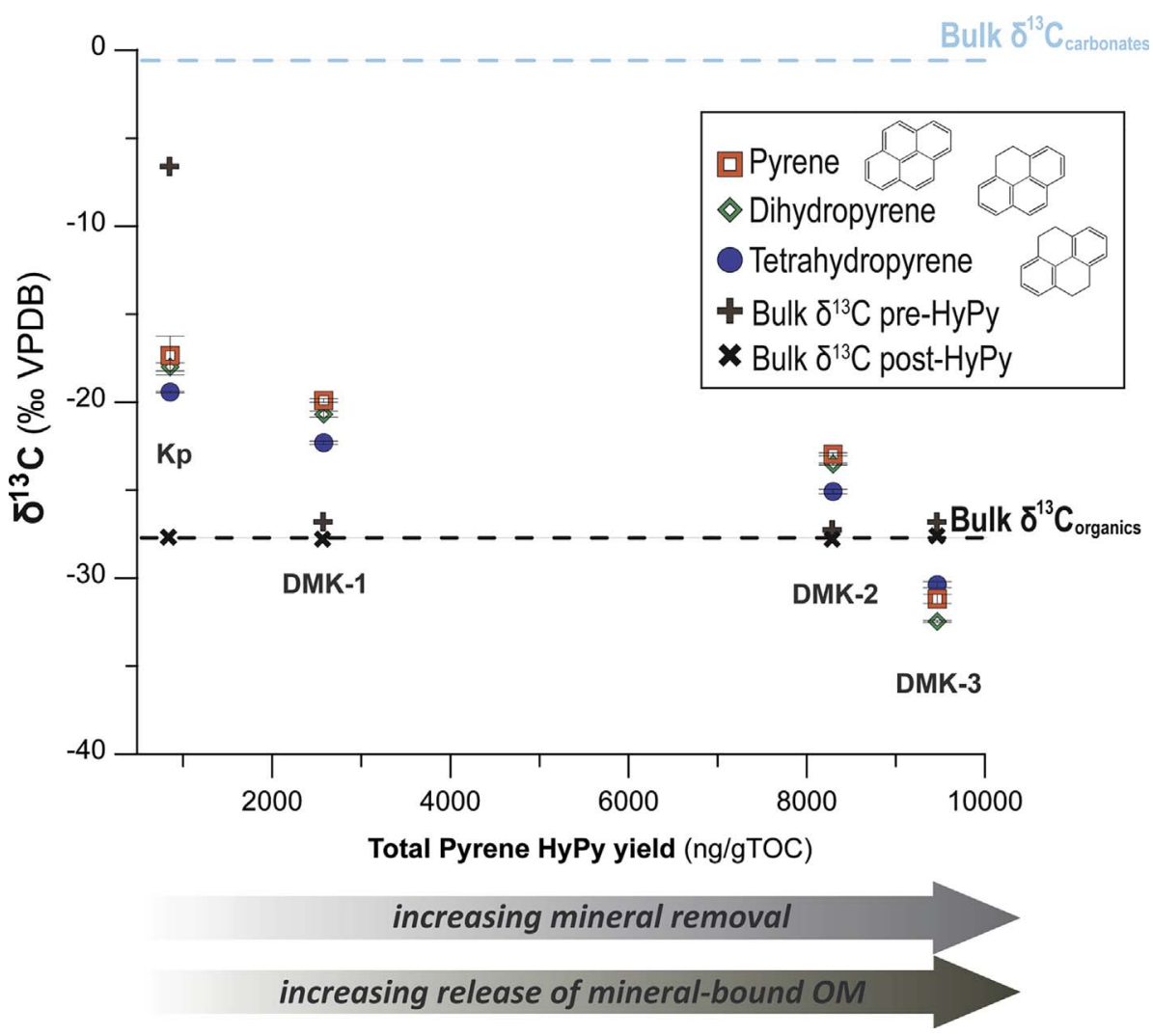

Fig. 12. CSIA of Pyrene, Dihydropyrene and Tetrahydropyrene (in \%o VPDB) products released by HyPy treatment of Kp and DMK1-3. Also shown are the bulk $\delta^{13} \mathrm{C}$ values of pre- and post-HyPy treated $\mathrm{Kp}$, demineralised fractions and isolated carbonates (calcite). 
$1245 \mathrm{~cm}^{-1}$ and $\mathrm{C}-\mathrm{C}$ aliphatic stretch at $1485 \mathrm{~cm}^{-1}$; Socrates, 2004) and may relate to $n$-alkane products also released by HyPy treatment of kerogen from CO-24 sediment (Robert et al., 2016).

Amorphisation involves the destruction of the graphitic sheets to produce amorphous carbons. The $\mathrm{G}$ peak, which is related to the relative motion (bond stretching) of $\mathrm{sp}^{2}$ pairs, was assumed to remain relatively constant with increasing amorphisation (Ferrari and Basko, 2013; Ferrari and Robertson, 2000). However, amorphisation can cause a notable dispersion in the $\mathrm{G}$ peak (Fig. $5 \mathrm{E}$ ) and this may be linked to the exceptionally high variance of observed $G_{F W H M}$ values across zones Z7-Z11 (Fig. 8; Table 3).

The HyPy released PAHs products showed a pronounced trend of increasing depletion in $\delta^{13} \mathrm{C}$ with each demineralisation step. For instance, the $\delta^{13} \mathrm{C}$ value of pyrene were $-17.3 \%$ (for $\mathrm{Kp}$ ), $-19.9 \%$ (DMK-1), -23.0\% (DMK-2) and -31.2\%o (DMK-3). HyPy based isotopic studies conducted on functionalised organic compounds from extant or immature sources identified negligible $\delta^{13} \mathrm{C}$ fractionation from the HyPy procedure (Sephton et al., 2005a,b). These trends therefore suggest that the PAHs products derive from two (or more) isotopically distinct sources: a heavy source with $\delta^{13} \mathrm{C} \geq-17.3 \%$ and a lighter source with $\delta^{13} \mathrm{C} \leq-31.2 \%$ based on the respective end member isotopic values. It is also important to note that each fraction may already be a mixture of the different $\mathbf{C M}_{f d}$ pools. The lighter source has a stronger mineral affinity (i.e. released in increasing concentration with progressive demineralisation) suggesting a potential connection to $\mathbf{C M}_{\boldsymbol{f}}$ that LR showed was concentrated in the sulfide mineral rich zones (Z7-Z11).

Different PAHs within $\mathbf{C M}_{f d}$ may have a varied mineral affinity. The sorption behaviour of PAHs onto mineral surfaces were conducted experimentally by Müller et al. (2007) and found that minerals contribute crucially to the retention PAHs in subsurface environment. Alternatively, the demineralisation procedures conducted in this study, similar to the extraction efficiency experiments conducted by Holman et al. (2012) may have contributed to a geochromatography effect where lighter ${ }^{12} \mathrm{C}$ come out after ${ }^{13} \mathrm{C}$. The strong connection of $\mathbf{C M}_{f d}$ to this lighter ${ }^{13} \mathrm{C}$ source and affinity to sulfide rich zone suggests that it may serve as a more specific $\mathrm{CM}$ indicator of Au deposits.

The post-HyPy residue of the parent and demineralised kerogens all had $\delta^{13} \mathrm{C}$ values of -27.6 ( \pm 0.1$) \%$ suggesting the efficient HyPy isolation of an organic residue that other research has shown to represent the black-C fraction of organic sediments (Ascough et al., 2009). The high temperatures applied during HyPy treatment efficiently releases carbonates which will contribute to the $\sim 3.5 \mathrm{TC}$ wt $\%$ decline measured in the kerogen fractions following HyPy treatment (Table 4). The lower \% TC wt. of DMK-2 and DMK-3 (Cf. Kp) was also attributed to the loss of the HyPy released aromatic and aliphatic hydrocarbons and potentially large proportions of non-detectable gases (e.g., $\mathrm{CH}_{4}$ and $\mathrm{CO}_{2}$ ).

The $\mathbf{C M}_{f d}$ in CO-24 may have derived (1) in situ from amorphisation of emplaced $\mathbf{C M}_{k e r}$ or (2) been introduced from zones exogenous to the deposit/formation of the CM bearing Koolpin Formation. The highlydisordered nature of $\mathbf{C M}_{\boldsymbol{f d}}$ could indicate that it was formed due to postmineralisation retrogression at very low temperatures, however the paragenetic relationship of $\mathbf{C M}_{\boldsymbol{f d}}$ to the sulfide minerals suggests otherwise. $\mathbf{C M}_{\boldsymbol{f d}}$ occurred as inclusions within the Au-bearing pyrites and arsenopyrites (i.e., SEM image Fig. 13A right) suggesting coeval deposition of $\mathbf{C M}_{f d}$ and the host mineral. Alternatively, PAH-rich OM may have been mobilised by the magmatic fluids associated with the emplacement of the Cullen Batholith or the contact metamorphic fluids associated with later structural reactivation and fluid flow. The multiple phases of granitic intrusion (fluids, heat) and deformation events caused the circulation of mineralised Au-bearing hydrothermal solutions (Partington and McNaughton, 1997). Regardless of the source, it is certain that $\mathbf{C M}_{\boldsymbol{f} \boldsymbol{d}}$ was formed by fluid driven reactions - metasomatic process that post-dates the $\mathbf{C M}_{\text {ker }}$ formation from large scale regional metamorphic events in Cosmo Howley.
Similar LR characteristics to $\mathbf{C M}_{\boldsymbol{f} \boldsymbol{d}}$ have been reported for previous LR analysis of several unusual types of CM. The R1 values measured by LR analysis of kerogens graphitised by regional metamorphism were reported to decrease (Jehlička et al., 2003) to the low values we have measured for $\mathbf{C M}_{k e r}$. Solid bitumens produced by high temperature metamorphism also showed limited structural or micro texture similar to the amorphous nature of $\mathbf{C M}_{\boldsymbol{f d}}$. The $\mathbf{R} \mathbf{1}$ values of these solid bitumen were relatively constant (Jehlička et al., 2003), but separate laboratory simulated maturation of amorphous solid bitumens did lead to a significant increase of R1 values from 0.7 to $>1.0$ and a shift in the D band position from $1360 \mathrm{~cm}^{-1}$ to $1325 \mathrm{~cm}^{-1}$ (Zhou et al.(2014) similar to what we observed for $\mathrm{CM}$ Group 3 ( $\mathrm{R} 1 \geq 1.5$, orange data points, Fig. 9), which we have attributed to $\mathbf{C M}_{\boldsymbol{f d}}$. Furthermore, the Raman spectra of $\mathbf{C M}_{\boldsymbol{f d}}$ (Figs. 6B, 7e) has a characteristic shape similar to the Raman spectra of amorphous $\mathrm{C}$ formed from the experimental hydrothermal treatment of $\alpha$-SiC crystals obtained by Kraft and Nickel (2000). Inorganic-organic interaction similar to those that can occur in $\mathrm{Au}$ mineralising hydrothermal systems could be responsible for the formation of Raman distinct amorphous, PAH rich $\mathbf{C M}_{\boldsymbol{f d}}$.

The mid-range $\mathbf{R} 1$ and $\mathbf{R 2}$ values indicative of CM Group 2 (grey points, Fig. 9) was attributed to a mixed $\mathbf{C M}_{k e r}$ and $\mathbf{C M}_{f d}$ signal and does reflect their varied distribution in CO-24 (e.g., $\mathbf{C M}_{f d}$ concentrated along edges and mineral boundaries). The current Raman analysis were limited by the microscope optics (i.e., objective/aperture) to sample areas of $<1 \mu \mathrm{m}$. Examples of CO-24 regions with different representations of $\mathbf{C M}_{k e r}, \mathbf{C M}_{f d}$ and surrounding minerals, and the spectra we attribute to them are shown in Fig. 13. A mixture of different CM types might also be responsible for CM-4, one of four CM types reported by Hu et al. (2015) in the Macraes Au deposit, that had similar magnitude $\mathbf{R} 1$ values to $\mathbf{C M}_{\boldsymbol{f d}}$.

\subsection{OM transformation in orogenic systems and its significance to $A u$ mineralisation}

The Cullen Batholith is a type-I, mantle derived, syn- to post-orogenic granitoid characterised as radiothermal with high concentrations of radioactive elements significantly above normal granites (Hollis and Wygralak, 2012). The elevated regional temperatures and complex and multiple deformation events before and following the intrusion led to the in situ transformation of indigenous OM to highly ordered $\mathbf{C M}_{\text {ker }}$. The high structural order and compact nature of this graphitic CM would aid the physical or chemical scavenging of Au subsequently introduced by hydrothermal fluids.

Heat from the intrusions and a prolonged cooling history coupled with pre-existing duplex thrust-fold structures allowed regional-scale hydrothermal systems to channel fluids, both from granites and the surrounding rocks. Later reactivation of the deformation structures due to transitional stresses resulted in the earliest recorded Au mineralisation event (Ahmad et al., 2009; Ewers et al., 1985; Hollis and Wygralak, 2012; Needham et al., 1988). Highly acidic hydrothermal fluids which transport $\mathrm{Au}$ and oxidizing hydrothermal fluids ideal for Au precipitation have been frequently detected in high temperature orogenic systems (Frimmel, 2005; Hodkiewicz et al., 2009; Pirajno and Bagas, 2008) and were a key element in the formation of gold deposits in the Pine Creek Orogen (Partington and McNaughton, 1997). The localisation of the amorphous PAH-rich $\mathbf{C M}_{\boldsymbol{f} d}$ to the hydrothermal and sulfide vein regions would be consistent with a hydrothermal fluid origin also responsible the deposition of the sulfide minerals.

Once deposited, $\mathbf{C M}_{\boldsymbol{f d}}$ may be altered by further metamorphism (contact; hydrothermally influenced). As discussed in Section 4.2.2, thermal maturation of similar amorphous (PAHs rich) CMs led to a significant increase of $\mathbf{R} \mathbf{1}$ values and a shift in the D band position. These changes may be explained by the clustering of the PAH networks (BSUs - see Fig. 4C-c for structure). Although, the clustering involved here is not equivalent to the growth of aromatic graphene sheets that would have resulted in lower D1 and higher G intensity. Instead an 
A

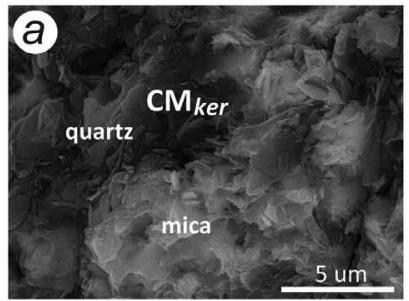

B
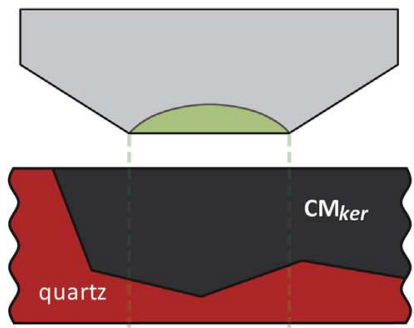

Raman Group 1

C

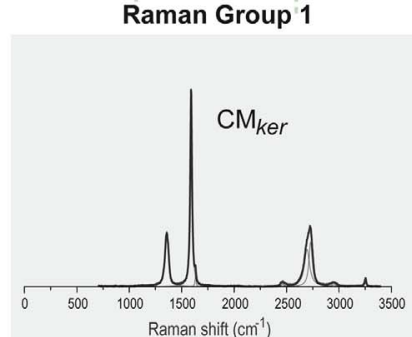

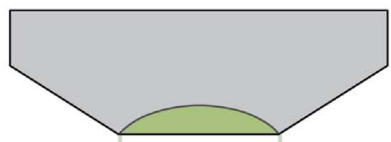

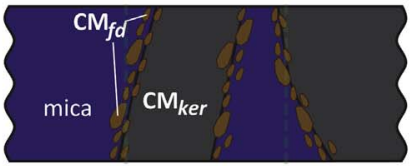

Raman Group 2

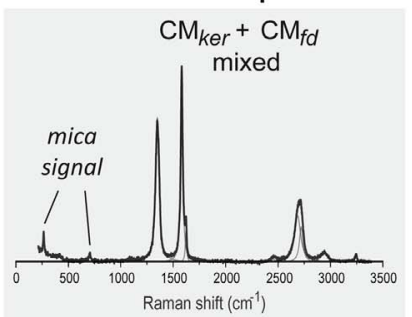

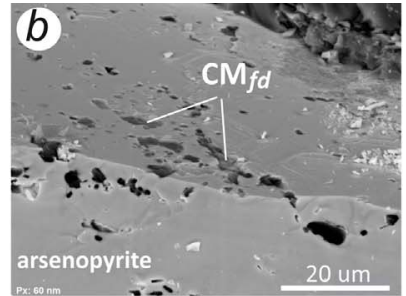
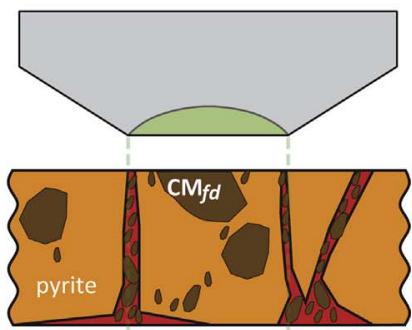

Raman Group 3

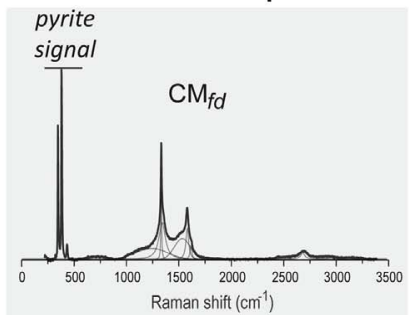

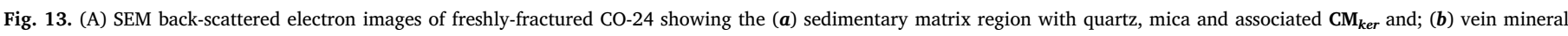

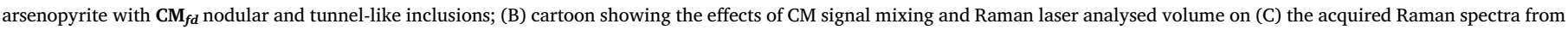
CO-24.

aggregation of BSUs or more intense $\mathrm{PAH}$ network within a zonal region resulted in an even more intensified D1 peak that in Raman structural terms is regarded as "more disordered C".

Gold can be deposited by either (i) transient rapid pressure drops; (ii) wall-rock interaction; or (iii) fluid mixing although this is unlikely for orogenic Au (McCuaig and Kerrich, 1998; Sibson et al., 1988). Rapid pressure release (encompassing the boiling mechanism) is likely one of the predominant processes responsible for the deposition of $\mathrm{Au}$ and sulfides at Cosmo-Howley given the extensive veining in the deposit (Matthäi et al., 1995a; Matthäi et al., 1995b). In the framework of a pressure drop, kinetic factors suggest hydrothermally dissolved organics would similarly precipitate. In the absence of shear stress and long exposures to regional metamorphism required to produce ordered CMs (i.e., graphite) the CM would precipitate in an amorphous form (i.e., $\mathbf{C M}_{f d}$ ) and develop higher disorder at increased thermal conditions (Bonijoly et al., 1982; Luque et al., 1998).

\subsection{Implications of using CM Raman data as a geothermometer}

The first order LR signals can be indicative of the degree of carbon crystallinity or structural order (Kwiecinska et al., 2010; Kwiecinska and Petersen, 2004; Luque et al., 1998; Wopenka and Pasteris, 1993) and several geothermometers have been proposed based on the relative intensities of the D1 and G peaks (Beyssac et al., 2002; Kouketsu et al., 2014; Rahl et al., 2005). This geothermometer application, however, would only seem valid for metamorphically controlled systems. The temperature derivation methods have typically been calibrated for high temperature systems ( $>200{ }^{\circ} \mathrm{C}$ ) and with only $\mathbf{C M}_{k e r}$ type of material, although quantifiable changes in laser Raman responses were recently reported in kerogens from an immature to mid-maturity sedimentary succession (Schito et al., 2017). Maturity estimates might be compromised for instance if the Raman analyses included a significant contribution of amorphous $\mathrm{C}$ such as the $\mathbf{C M}_{\boldsymbol{f} d}$ detected in CO-24. The thermal transformation of amorphous, $\mathrm{PAH}$ rich $\mathbf{C M}_{f d}$, in hydrothermal/contact metamorphic systems would lead to an increased D1 peak, in direct contrast to the weakening of this signal with the metamorphic graphitisation of CM.

Geological temperatures of the three Raman data groups separately calculated with three different calibration equations (Beyssac et al., 2002; Rahl et al., 2005; Kouketsu et al., 2014) gave different temperature ranges (Fig. 14A): i) $\sim 300-500{ }^{\circ} \mathrm{C}$ using the equation proposed by Beyssac et al. (2002); ii) $\sim 350-500{ }^{\circ} \mathrm{C}$ from the Rahl et al. (2005) equation with an exceptionally low $\sim 50{ }^{\circ} \mathrm{C}$ near $\mathrm{Z7}$ and high $\sim 550{ }^{\circ} \mathrm{C}$ at $\mathrm{Z11}$; and iii) a narrow range around $450{ }^{\circ} \mathrm{C}$ across all zones (except $<300{ }^{\circ} \mathrm{C}$ for Z11) by the Kouketsu et al. (2014) formulation. These temperature estimates were all lower than the actual metamorphic temperatures of $550{ }^{\circ} \mathrm{C}$ measured by traditional methods (e.g., mineralogy, fluid inclusion).

Separate application of these geothermometer formulas to just $\mathbf{C M}_{\text {ker }}$ or $\mathbf{C M}_{\text {fd }}$ (Fig. 14B) identified their respective contribution to the temperature calculations. The highest temperatures within a range of $\sim 400-600{ }^{\circ} \mathrm{C}$ were consistently obtained from $\mathbf{C M}_{\text {ker }}$. $\mathbf{C M}_{\text {fd }}$ based calculations extended to much lower temperatures of $50-450{ }^{\circ} \mathrm{C}$, which significantly underestimated the thermal history of the deposit. Clearly, LR signals from just $\mathbf{C M}_{\text {ker }}$ (blue data points, Fig. 9) are the most indicative of the true thermal history of the deposit. Intermediate temperatures could be implied from a mixed of $\mathbf{C M}_{f d}$ and $\mathbf{C M}_{k e r}$ signal. The presence of $\mathbf{C M}_{\boldsymbol{f} \boldsymbol{d}}$ significantly compromises the thermal evaluation of the deposit highlighting that proper identification and evaluation of CM types should be conducted before the application of any Raman based geothermometer formulas. Of course where advanced analytical approaches used here (i.e., nano-scale imaging) is not possible the geothermometer method from Kouketsu et al. (2014) may suffice for a general appraisal of carbon nature. 
A. Calculated CM Raman Temperatures [ $\left.{ }^{\circ} \mathrm{C}\right]$ across transect zones
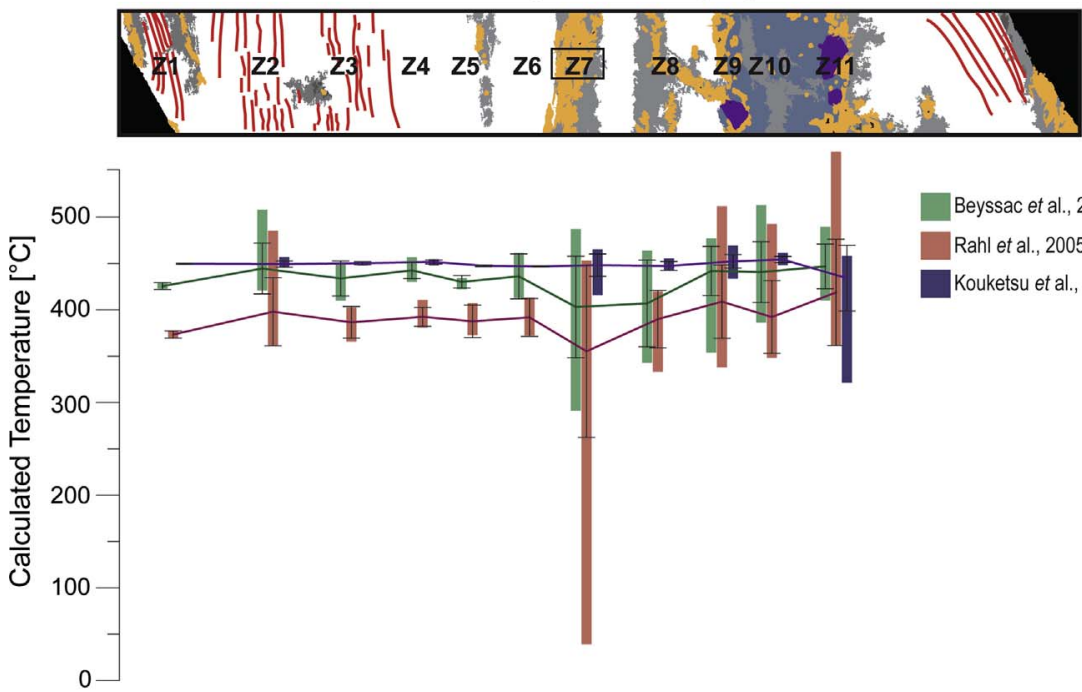

Fig. 14. Raman temperatures calculated (A) across different assigned zones in CO-24 thin section 1 and (B) using the different CM Types presently identified.

\section{B. Calculated metamorphic temperatures $\left[{ }^{\circ} \mathrm{C}\right]$ based on CM Types}

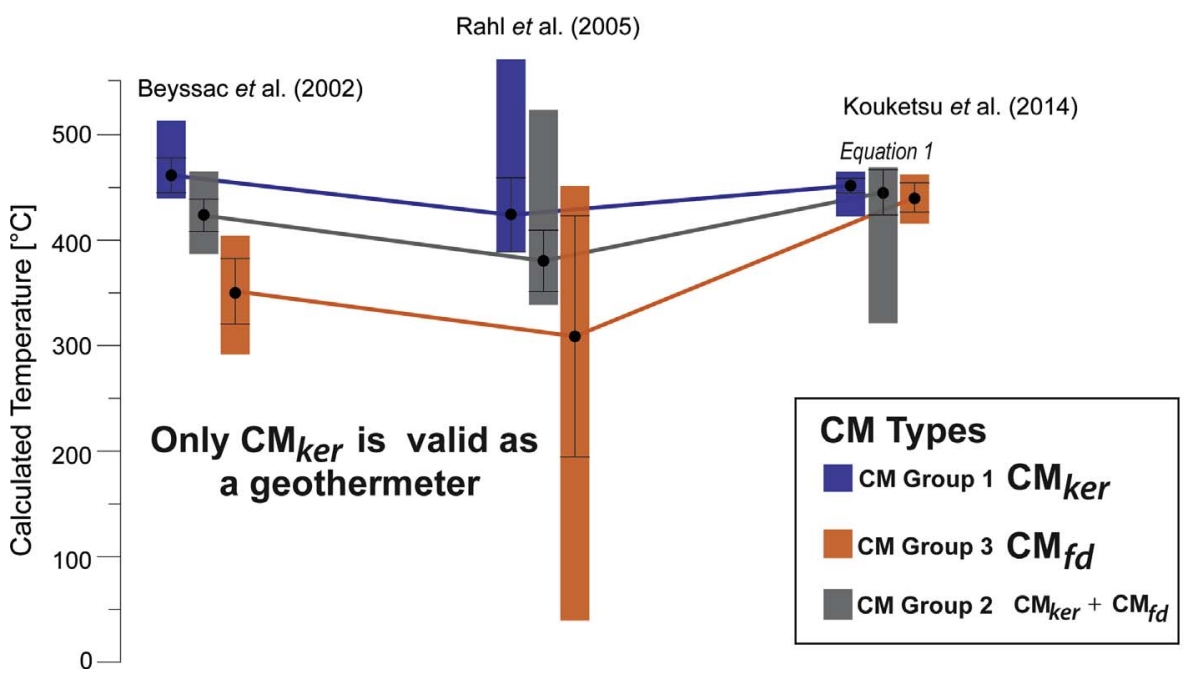

\section{Conclusions}

The local lithological $(\mathrm{mm})$ occurrence in a sediment core from the Cosmo Howley orogenic Au deposit of a metamorphic gradient from low to medium metamorphic grade CM (Fig. 7) suggested by the Raman data was inconsistent with the extreme thermal history $\left(>550{ }^{\circ} \mathrm{C}\right.$ ) of the orogenic deposit.

Whereas laser Raman analysis suggested the sedimentary occurrence of a broad range of low to high metamorphic CM grades which were separated into three distinctive groups based on R1 values (intensity D1/G bands), higher resolution nano-imaging identified just two distinct $\mathrm{CM}$ morphologies: $\mathbf{C M}_{\text {ker }}$ graphitised under regional metamorphic conditions; and amorphous PAH rich specks or nodules of $\mathbf{C M}_{f d}$. A third CM group implied by LR was attributed to a mixture of $\mathbf{C M}_{\text {ker }}$ and $\mathbf{C M}_{f d}$, and served to demonstrate that the common practice of laser Raman based CM classification should be considered with some caution.

The co-integration of the combined high resolution in situ LR analysis, detailed microscopy, nanoscale imaging and hydropyrolysis of CO-24 indicated that $\mathbf{C M}_{\boldsymbol{f} d}$ was an amorphous PAH rich a hydrothermally deposited CM.

The metamorphic and hydrothermal history of the deposit gave rise to $\mathbf{C M}_{\boldsymbol{k} \text { r }}$ and $\mathbf{C M}_{\boldsymbol{f d}}$ with different structural behaviour that was reflected by the laser Raman data. Only the Raman data from $\mathbf{C M}_{k e r}$ should be used for a valid and reliable assessment of regional metamorphic conditions and geothermometer application, requiring $\mathbf{C M}_{k e r}$ to be analytically resolved from other $\mathrm{CM}$ types.

$\delta^{13} \mathrm{C}$ of HyPy fractions of CO-24 sediments identified PAHs present which derive from at least two separate organic sources. HyPy treatment of kerogens released increasing abundance of PAHs from a relatively ${ }^{13} \mathrm{C}$ depleted source $(\leq-31.2 \%$ ) with aggressive demineralisation. The strong mineral affinity of this source suggests a potential link to the sulfide mineral rich zones where $\mathbf{C M}_{f d}$ was concentrated. In this event the $\mathbf{C M}_{f d}$ may serve as an indicator of Au-rich regions/deposits, although the exact relationship between $\mathrm{Au}$ and $\mathbf{C M}_{\boldsymbol{f}}$ is yet to be established. A second heavier source of PAHs (i.e. parent kerogen $(-16$ to $-20 \%$ ) and DMK-1 ( -20 to $-23 \% 0)$ ) suggests an alternative source or sub-fractions with different mineral affinities.

The isolated black C residue following HyPy treatment of all kerogen fractions was representative $\mathbf{C M}_{\text {ker }}$. It consistently had $\delta^{13} \mathrm{C}$ values of $\sim-27 \%$ that was also indicative of an organic source.

The laser Raman analysis (spatial resolution $0.3 \mu \mathrm{m}$ )could not be conducted at the same nanoscale (atomic scale) as the HRTEM imaging techniques $(<1 \mathrm{~nm})$ that allowed the distinct identification of $\mathbf{C M}_{f d}$ and $\mathbf{C M}_{\boldsymbol{k} \text { rer }}$, nor could HyPy be conducted at the scale of the LR analysis, which showed different distributions of $\mathbf{C M}_{f d}$ and $\mathbf{C M}_{k e r}$, Despite the 
different spatial resolution of these analytical techniques, they do contribute to a complimentary characterisation of CM, and should be used together in integrated studies where possible.

We have identified a structurally distinctive and hydrothermally deposited form of organic matter $\left(\mathbf{C M}_{\boldsymbol{f d}}\right)$ intimately associated paragenetically with $\mathrm{Au}$ and sulfides that should be a prioritised analytical target for further investigations of organic-inorganic interactions in mineral systems and the role of organic matter in mineralisation processes.

\section{Acknowledgements}

We thank Dr. Martin Hendriks and Dr. Aaron Dodd (CMCA), Dr. Animesh Basak (Adelaide Microscopy), Dr. Alex Hollman and Geoff Chidlow (WA-OIGC) for technical assistance. We acknowledge the CSIRO Minerals Down Under Flagship for federal funded support of the Organic Geochemistry of Minerals System Cluster (OGMS). We acknowledge the use of facilities, and the scientific and technical assistance of the Australian Microscopy \& Microanalysis Research Facility at the Centre for Microscopy, Characterisation \& Analysis (CMCA), The University of Western Australia; and at Adelaide Microscopy, The University of Adelaide, both facilities funded by the University, State and Commonwealth Governments. We also acknowledge the Australian Research Council (ARC) for the LIEFP grants (LE110100119, LE110100189, LE0775650, LE0775642, LE0668345, LE0560734) related to the organic geochemistry component of this research at WAOIGC, Curtin University. AMR thanks the University of Western Australia (UWA) and CSIRO for student scholarship. This paper forms contribution 997 of the Australian Research Council Centre of Excellence for Core to Crust Fluid Systems (http://www.ccfs.mq.edu. au). Finally, we thank the journal editor (Prof. Parrish) and three anonymous journal reviewers for their advice which improved this account of our study.

\section{References}

Ahmad, M., Hollis, J.A., 2013. Geology and mineral resources of the Northern Territory. In: Ahmad, M., Munson, T.J. (Eds.), Geology and Mineral Resources of the Northern Territory. Northern Territory Geological Survey.

Ahmad, M., Wygralak, A., Ferenczi, P., 2009. Gold Deposits of the Northern Territory. Northern Territory Geological Survey, Darwin.

Ascough, P.L., Bird, M.I., Brock, F., Higham, T.F.G., Meredith, W., Snape, C.E., Vane, C.H., 2009. Hydropyrolysis as a new tool for radiocarbon pre-treatment and the quantification of black carbon. Quat. Geochronol. 4, 140-147.

Bajwah, Z., 1994. A Contribution of geology, petrology and geochemstry to The Cullen Batholith and Related Hydrothermal Activity Responsible for the Mineralization, Pine Creek geosyncline, northern territory. North. Territ. Geol. Surv. Report 8.

Beams, R., Canç Ado, L.G., Novotny, L., 2015. Raman characterization of defects and dopants in graphene. J. Phys.: Condens. Matter 27, 83002. http://dx.doi.org/10. 1088/0953-8984/27/8/083002.

Beyssac, O., Goffé, B., Chopin, C., Rouzaud, J.N., 2002. Raman spectra of carbonaceous material in metasediments: a new geothermometer. J. Metamorph. Geol. 20 859-871.

Beyssac, O., Goffé, B., Petitet, J.-P., Froigneux, E., Moreau, M., Rouzaud, J.-N., 2003. On the characterization of disordered and heterogeneous carbonaceous materials by Raman spectroscopy. Spectrochim. Acta A Mol. Biomol. Spectrosc. 59, 2267-2276.

Bokobza, L., Bruneel, J.-L., Couzi, M., 2013. Raman spectroscopic investigation of carbonbased materials and their composites. Comparison between carbon nanotubes and carbon black. Chem. Phys. Lett. 590, 153-159. http://dx.doi.org/10.1016/j.cplett. 2013.10.071.

Bokobza, L., Bruneel, J.-L., Couzi, M., 2015. Raman spectra of carbon-based materials (from graphite to carbon black) and of some silicone composites. Carbon N. Y. 1, 77-94. http://dx.doi.org/10.3390/c1010077.

Bonijoly, M., Oberlin, M., Oberlin, A., 1982. A possible mechanism for natural graphite formation. Int. J. Coal Geol. 1, 283-312. http://dx.doi.org/10.1016/0166-5162(82) 90018-0.

Casiraghi, C., Ferrari, A.C., Robertson, J., 2005. Raman spectroscopy of hydrogenated amorphous carbons. Phys. Rev. B 72, 85401. http://dx.doi.org/10.1103/PhysRevB. 72.085401 .

Castiglioni, C., Mapelli, C., Negri, F., Zerbi, G., 2001a. Origin of the D line in the Raman spectrum of graphite: a study based on Raman frequencies and intensities of polycyclic aromatic hydrocarbon molecules. J. Chem. Phys. 114, 963-974. http://dx.doi org/10.1063/1.1329670.

Castiglioni, C., Negri, F., Tommasini, M., Di Donato, E., Zerbi, G., 2001b. Effect of the confinement on the structure of graphitic clusters: a study based on Raman spectroscopy of large polycyclic aromatic hydrocarbons. In: In: Mesina, G., Santangelo, S. (Eds.), GNSR 2001: State of Art and Future Development in Raman Spectroscopy and Related Techniques IOS Press, Tokyo, pp. 15-27 Amsterdam; Washington, D.C. Ohmsha, (C) 2002.

Colangeli, L., Mennella, V., Baratta, G.A., Bussoletti, E., Strazzulla, G., 1992. Raman and infrared spectra of polycyclic aromatic hydrocarbon molecules of possible astrophysical interest. Astrophys. J. 396, 369-377. http://dx.doi.org/10.1086/171723.

Craw, D., Windle, S., Angus, P., 1999. Gold mineralization without quartz veins in a ductile-brittle shear zone, Macraes Mine, Otago Schist, New Zealand. Miner. Deposita 34, 382-394.

Cuesta, A., Dhamelincourt, P., Laureyns, J., Martínez-Alonso, A., Tascón, J.M.D., 1994. Raman microprobe studies on carbon materials. Carbon N. Y. 32, 1523-1532. http:// dx.doi.org/10.1016/0008-6223(94)90148-1.

Cyvin, S.J., Cyvin, B.N., Brunvoll, J., 1982. Condensed aromatics. Part XX. Coronene. Z. Naturforsch $37,1359-1368$.

Dissanayake, C.B., 1993. Gold and other metals in graphite. Spec. Publ. Soc. Geol. Appl. Miner. Depos. 9, 138-152 ST-Gold and other metals in graphite.

Dresselhaus, M.S., Jorio, A., Souza Filho, A.G., Saito, R., 2010. Defect characterization in graphene and carbon nanotubes using Raman spectroscopy. Philos. Trans. R. Soc. London, Ser. A 368, 5355-5377. http://dx.doi.org/10.1098/rsta.2010.0213.

Eckmann, A., Felten, A., Mishchenko, A., Britnell, L., Krupke, R., Novoselov, K.S., Casiraghi, C., 2012. Probing the nature of defects in graphene by Raman spectroscopy. Nano Lett. 12, 3925-3930. http://dx.doi.org/10.1021/nl300901a.

Ewers, G., Needham, R.S., Stuart-Smith, P., Crick, I., 1985. Geochemistry of the low-grade Early Proterozoic sedimentary sequence in the Pine Creek Geosyncline, Northern Territory. Aust. J. Earth Sci. 32, 37-41.

Ferrari, A.C., 2007. Raman spectroscopy of graphene and graphite: disorder, electronphonon coupling, doping and nonadiabatic effects. Solid State Commun. 143, 47-57. http://dx.doi.org/10.1016/j.ssc.2007.03.052.

Ferrari, A., Basko, D., 2013. Raman spectroscopy as a versatile tool for studying the properties of graphene. Nat. Nanotechnol. 8, 235-246. http://dx.doi.org/10.1038/ nnano.2013.46.

Ferrari, A., Robertson, J., 2000. Interpretation of Raman spectra of disordered and amorphous carbon. Phys. Rev. B 61, 95-107.

Fetzer, W.G., 1934. Transportation of gold by organic solutions. Econ. Geol. 29, 599-604.

Fetzer, W., 1946. Humic acids and true organic acids as solvents of minerals. Econ. Geol. 2, 97-103.

Freise, F., 1931. The transportation of gold by organic underground solutions. Econ. Geol 26, 421-431.

Frimmel, H.E., 2005. Archaean atmospheric evolution: Evidence from the Witwatersrand gold fields, South Africa. Earth Sci. Rev. http://dx.doi.org/10.1016/j.earscirev.2004. 10.003 .

Garvie, L.A.J., Craven, A.J., Brydson, R., 1994. Use of electron-energy loss near-edge fine structure in the study of minerals. Am. Mineral. 79, 411-425.

Gatellier, J.-P., Disnar, J.-R., 1989. Organic matter and gold-ore association in a hydrothermal deposit, France. Appl. Geochem. 4, 143-149.

Gize, A., 2000. The organic geochemistry of gold, platinum, uranium and mercury deposits. In: Giordano, T.H. (Ed.), Ore Genesis and Exploration: The Roles of Organic Matter. pp. 217-250.

Goldfarb, R.J., Groves, D.I., Gardoll, S., 2001. Orogenic gold and geologic time: a global synthesis. Ore Geol. Rev. 18, 1-75.

Greenwood, P.F., Brocks, J.J., Grice, K., Schwark, L., Jaraula, C.M.B., Dick, J.M., Evans, K.A., 2013. Organic geochemistry and mineralogy. I. Characterisation of organic matter associated with metal deposits. Ore Geol. Rev. 50, 1-27.

Gregoire, D., 1985. Selective extraction of organically bound gold in soils, lake sediment and stream sediments. J. Geochem. Explor. 23, 299-313.

Grotheer, H., Robert, A.M., Greenwood, P.F., Grice, K., 2015. Stability and hydrogenation of polycyclic aromatic hydrocarbons during hydropyrolysis (HyPy) - relevance for high maturity organic matter. Org. Geochem. 86, 45-54.

Groves, D.I., Goldfarb, R.J., Robert, F., Hart, C.J.R., 2003. Gold deposits in metamorphic belts: overview of current understanding, outstanding problems, future research, and exploration significance. Econ. Geol. http://dx.doi.org/10.2113/gsecongeo.98.1.1.

Henne, A., Craw, D., 2012. Synmetamorphic carbon mobility and graphite enrichment in metaturbidites as a precursor to orogenic gold mineralisation, Otago Schist, New Zealand. Miner. Deposita 47, 781-797. http://dx.doi.org/10.1007/s00126-0120399-2.

Hodkiewicz, P.F., Groves, D.I., Davidson, G.J., Weinberg, R.F., Hagemann, S.G., 2009. Influence of structural setting on sulphur isotopes in Archean orogenic gold deposits, Eastern Goldfields Province, Yilgarn, Western Australia. Miner. Deposita 44, 129-150. http://dx.doi.org/10.1007/s00126-008-0211-5.

Hollis, J., Wygralak, A., 2012. A review of the geology and uranium, gold and iron ore deposits of the Pine Creek Orogen. Episodes 35, 264-272.

Holman, A.I., Grice, K., Jaraula, C.M.B., Schimmelmann, A., Brocks, J.J., 2012. Efficiency of extraction of polycyclic aromatic hydrocarbons from the Paleoproterozoic Here's Your Chance $\mathrm{Pb} / \mathrm{Zn} / \mathrm{Ag}$ ore deposit and implications for a study of Bitumen II. Org. Geochem. 52, 81-87.

Hu, S., Evans, K., Craw, D., Rempel, K., Bourdet, J., Dick, J., Grice, K., 2015. Raman characterization of carbonaceous material in the Macraes orogenic gold deposit and metasedimentary host rocks, New Zealand. Ore Geol. Rev. 70, 80-95.

Jehlička, J., Urban, O., Pokorný, J., 2003. Raman spectroscopy of carbon and solid bitumens in sedimentary and metamorphic rocks. Spectrochim. Acta, Part A 59, 2341-2352. http://dx.doi.org/10.1016/S1386-1425(03)00077-5.

Kouketsu, Y., Mizukami, T., Mori, H., Endo, S., Aoya, M., Hara, H., Nakamura, D., Wallis, S., 2014. A new approach to develop the Raman carbonaceous material geothermometer for low-grade metamorphism using peak width. Island Arc 23, 33-50. http:// dx.doi.org/10.1111/iar.12057. 
Kraft, T., Nickel, K.G., 2000. Carbon formed by hydrothermal treatment of $\alpha$-SiC crystals. J. Mater. Chem. 10, 671-680. http://dx.doi.org/10.1039/a908030i.

Kř́bek, B., Sýkorová, I., Machovič, V., Knésl, I., Laufek, F., Zachariáš, J., 2015. The origin and hydrothermal mobilization of carbonaceous matter associated with Paleoproterozoic orogenic-type gold deposits of West Africa. Precambrian Res. 270 300-317. http://dx.doi.org/10.1016/j.precamres.2015.09.017.

Kwiecinska, B., Petersen, H.I., 2004. Graphite, semi-graphite, natural coke, and natural char classification-ICCP system. Int. J. Coal Geol. 57, 99-116. http://dx.doi.org/10. 1016/j.coal.2003.09.003.

Kwiecinska, B., Suárez-Ruiz, I., Paluszkiewicz, C., Rodriques, S., 2010. Raman spectroscopy of selected carbonaceous samples. Int. J. Coal Geol. 84, 206-212. http://dx.doi. org/10.1016/j.coal.2010.08.010.

Luo, Z., Cong, C., Zhang, J., Xiong, Q., Yu, T., 2012. The origin of sub-bands in the Raman D-band of graphene. Carbon N. Y. 50, 4252-4258. http://dx.doi.org/10.1016/j. carbon.2012.05.008.

Luque, F.J., Pasteris, J.D., Wopenka, B., Rodas, M., Barrenechea, J.F., 1998. Natural fluid deposited graphite: mineralogical characteristics and meachanisms of formation. Am. J. Sci. 298, 471-498. http://dx.doi.org/10.2475/ajs.298.6.471.

Maghsoumi, A., Narita, A., Dong, R., Feng, X., Castilioni, C., Mullen, K., Tommasini, M., 2016. Edge chlorination of hexa-peri-hexabenzocoronene investigated by density functional theory and vibrational spectroscopy. R. Soc. Chem. 18, 11869-11878. http://dx.doi.org/10.1039/C5CP07755A.

Mapelli, C., Castiglioni, C., Zerbi, G., Müllen, K., 1999. Common force field for graphite and polycyclic aromatic hydrocarbons. Phys. Rev. B 60, 12710. http://dx.doi.org/10. 1103/PhysRevB.60.12710.

Matthäi, S.K., Henley, R.W., 1996. Geochemistry and depositional environment of the gold-mineralized Proterozoic Koolpin Formation, Pine Creek Inlier, Northern Australia: a comparison with modern shale sequences. Precambrian Res. 78, 211-235.

Matthäi, S.K., Henley, R.W., Bacigalupo-Rose, S., Binns, R.A., Andrew, A.S., Carr, G.R., French, D.H., McAndrew, J., Kananagh, M., 1995a. Intrusion-related, high-temperature gold quartz veining in the Cosmopolitan Howley metasedimentary rock-hosted gold deposit, Northern Territory, Australia. Econ. Geol. 90, 1012-1045.

Matthäi, S.K., Henley, R.W., Heinrich, C.A., 1995b. Gold precipitation by fluid mixing in bedding-parallel fractures near carbonaceous slates at the Cosmopolitan Howley gold deposit, northern Australia. Econ. Geol. 90, 2123-2142.

Mayo, D.W., Miller, F.A., Hannah, R.W., 2004. Course Notes on the Interpretation of Infrared and Raman Spectra, Book. doi:10.1002/0471690082.ch1.

McCreery, R., n.d. Standard Spectra [WWW Document]. webpage. < http://www.chem. ualberta.ca/ mccreery/ramanmaterials.html\#cyclohexane $>$ (accessed 1.6.17).

McCuaig, T., Kerrich, R., 1998. PTt-deformation-fluid characteristics of lode gold deposits: evidence from alteration systematics. Ore Geol. Rev. 12, 381-453.

Mossman, D., 1999. Carbonaceous substances in mineral deposits: implications for geochemical exploration. J. Geochem. Explor. 66, 241-247.

Müller, S., Totsche, K.U., Kögel-Knabner, I., 2007. Sorption of polycyclic aromatic hydrocarbons to mineral surfaces. Eur. J. Soil Sci. 58, 918-931. http://dx.doi.org/10. 1111/j.1365-2389.2007.00930.x.

Needham, R., Stuart-Smith, P., Page, R., 1988. Tectonic evolution of the Pine Creek Inlier, Northern Territory. Precambrian Res. 41, 543-564.

Parnell, J., McCready, A., 2000. Paragenesis of gold-and hydrocarbon-bearing fluids in gold deposits. In: Glikson, M., Mastalerz, M. (Eds.), Organic Matter and Mineralization: Thermal Alteration, Hydrocarbon Generation and Role in Metallogenesis. Springer, Netherlands, pp. 38-52.

Partington, G., McNaughton, N., 1997. Controls on mineralisation in the Howley District, Northern territory: a link between granite intrusion and gold mineralisation. Chron. la Rech. Min. 529, 25-44.

Pawlyta, M., Rouzaud, J., Duber, S., 2015. Raman microspectroscopy characterization of carbon blacks: spectral analysis and structural information. Carbon N. Y. 84, 479-490. http://dx.doi.org/10.1016/j.carbon.2014.12.030.

Pirajno, F., Bagas, L., 2008. A review of Australia's Proterozoic mineral systems and genetic models. Precambrian Res. 166, 54-80. http://dx.doi.org/10.1016/j. precamres.2007.05.008

Rahl, J., Anderson, K., Brandon, M., Fassoulas, C., 2005. Raman spectroscopic carbonaceous material thermometry of low-grade metamorphic rocks: calibration and application to tectonic exhumation in Crete, Greece. Earth Planet. Sci. Lett. 240, 339-354.

Reich, S., Thomsen, C., 2004. Raman spectroscopy of graphite. Philos. Trans. A. Math Phys. Eng. Sci. 362, 2271-2288. http://dx.doi.org/10.1098/rsta.2004.1454.

Robert, A.M., Grotheer, H., Greenwood, P.F., McCuaig, T.C., Bourdet, J., Grice, K., 2016. The hydropyrolysis (HyPy) release of hydrocarbon products from a high maturity kerogen associated with an orogenic Au deposit and their relationship to the mineral matrix. Chem. Geol. 425, 127-144. http://dx.doi.org/10.1017/CBO9781107415324. 004.

Sadezky, A., Muckenhuber, H., Grothe, H., Niessner, R., Pöschl, U., 2005. Raman microspectroscopy of soot and related carbonaceous materials: spectral analysis and structural information. Carbon N. Y. 43, 1731-1742. http://dx.doi.org/10.1016/j carbon.2005.02.018.

Schito, A., Romano, C., Corrado, S., Grigo, D., Poe, B., 2017. Diagenetic thermal evolution of organic matter by Raman spectroscopy. Org. Geochem. 106, 57-67. http://dx.doi. org/10.1016/j.orggeochem.2016.12.006.

Sephton, M.A., Meredith, W., Sun, C.G., Snape, C.E., 2005a. Hydropyrolysis as a preparative method for the compound-specific carbon isotope analysis of fatty acids. Rapid Commun. Mass Spectrom. 19, 323-325. http://dx.doi.org/10.1002/rcm.1788.

Sephton, M.A., Meredith, W., Sun, C.G., Snape, C.E., 2005b. Hydropyrolysis of steroids: a preparative step for compound-specific carbon isotope ratio analysis. Rapid Commun. Mass Spectrom. 19, 3339-3342. http://dx.doi.org/10.1002/rcm.2201.

Seward, T., 1973. Thio complexes of gold and the transport of gold in hydrothermal ore solutions. Geochim. Cosmochim. Acta 87, 379-399.

Shimanouchi, T., 1973. Tables of molecular vibrational frequencies consolidated volume I. J. Phys. Chem. Ref. Data 2, 121-162. http://dx.doi.org/10.1063/1.3253114.

Sibson, R.H., Robert, F., Poulson, K.M., 1988. High angle reverse faults, fluid pressure cycling and mesothermal gold deposits. Geology 16, 551-555. http://dx.doi.org/10 1130/0091-7613(1988).

Skrzypek, G., 2013. Normalization procedures and reference material selection in stable HCNOS isotope analyses - an overview. Anal. Bioanal. Chem. 405, 2815-2823.

Skrzypek, G., Paul, D., Debajyoti, P., 2006. D13C analyses of calcium carbonate: comparison between the GasBench and elemental analyzer techniques. Rapid Commun. Mass Spectrom. 20, 2915-2920.

Socrates, G., 2004. Infrared and Raman Characteristic Group Frequencies, 3rd ed. John Wiley \& Sons 10.1002/jrs.1238.

Springer, J., 1985. Carbon in Archean rocks of the Abitibi belt (Ontario-Quebec) and its relation to gold distribution. Can. J. Earth Sci. 1945-1951.

Teichmüller, M., 1986. Organic petrology of source rocks, history and state of the art. Adv. Org. Geochem. 10, 581-599.

Tuinstra, F., Koenig, L., 1970. Raman spectrum of graphite. J. Chem. Phys. 53, 1126-1130. http://dx.doi.org/10.1063/1.1674108.

Wopenka, B., Pasteris, J.D., 1993. Structural characterization of kerogens to granulitefacies graphite: applicability of Raman microprobe spectroscopy. Am. Mineral. 78, 533-557.

Wygralak, A., Mernagh, T., Houston, D., Ahmad, M., 2005. Gold mineral systems of the Tanami region. North. Territ. Geol. Surv. Report 18.

Yan, Z., Barron, A.R., 2010. Characterization of Graphene by Raman Spectroscopy. OpenStax-CNX 1-4. doi:content/m34667/1.2/.

Zhao, X.M., Zhang, J., Berlie, A., Qin, Z.X., Huang, Q.W., Jiang, S., Zhang, J.B., Tang, L.Y., Liu, J., Zhang, C., Zhong, G.H., Lin, H.Q., Chen, X.J., 2013. Phase transformations and vibrational properties of coronene under pressure. J. Chem. Phys. 139. http://dx. doi.org/10.1063/1.4824384.

Zhou, Q., Xiao, X., Pan, L., Tian, H., 2014. The relationship between micro-Raman spectral parameters and reflectance of solid bitumen. Int. J. Coal Geol. 121, 19-25. http://dx.doi.org/10.1016/j.coal.2013.10.013. 